BHL 19289

AADD 74-9

\title{
A CHRONICLE OF SUPERCONDUCTING DEVICES AT BNL
}

\author{
P.F. DAFL
}

Augest 14, 1974

IHFORMAL REPORT

ACCELERATOR DEPARTMENT

BROOKHAVEN NATIONAL LABORATORY ASSOCIATED UNIVERSITIES, INC. UPTON, NEW YORK 11973 


\section{BROOKHAVEN NATIONAL LABORATORY Associated Universities, Inc. Upton, New York}

\section{ACCELERATOR DEPARTMENT Informal Report}

AADD 74-9

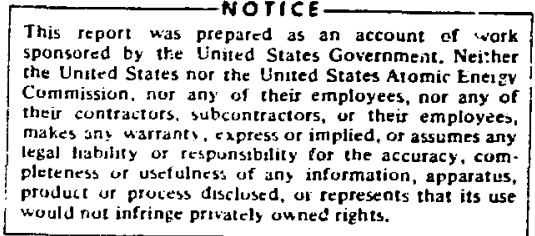

A CHRONICLE OF SUPERCONDUCTING LEVICES AT BNL

P. F. Dahl

August 14, 1974

ABSTRACT

The various ongoing programs in applied superconductivity supported by BNI are summarized, including the development of high field ac and dc superconducting magnets for accelerators and other applications, microwave deflecting cavities for high energy particle beam separators, cables for underground power transmission, and a materials research effort pursuing methods of fabricating new superconductors and metallurgical properties affecting the performance of superconducting devices.

\section{N O T I C E}

This report was prepared as an account of work sponsored by the United States Government. Neither the United States nor the United States Atomic Energy Commission, nor any of their employees, nor any of their contractors, subcontractors, or their employees, makes any warranty, express or implied, or assumes any legal liability or responsibility for the accuracy, completeness or usefulness of any information, apparatus, product or process disclosed, or represents that its use would not infringe privately owned rights. 


\section{Introduction}

We present here a brief account of the various programs in applied superconductivity supported by the Laboratory over the past decade or so; namely, applications embracing $d c$ and ac general and special purpose magnets, metallurgy, rf cavities and power transmission. Emphasis has been placed on magnet development and on particular devices, selected as much ior their illustration of important techniques or principles as for their utility. The order is essentially arbitrary but chosen to give an indication of the historical sequence. By way of introduction we summarize some of the basic factors influencing superconducting magnet construction, especially current density and stabilization.

Superconductors are classified as either type I or type II, according to their behavior when in the presence of a magnetic field. Members of the first class are also known as "ideal" or "soft" superconductors, and include compounds and many pure metals. Among the latter is the first superconductor discovered (mercury, in 1911). The second class contains the "hard" or "highfield" superconductors, including most superconducting alloys and compounds. Below a transition temperature $\mathrm{T}_{\mathrm{c}}$, generally not exceeding $10 \mathrm{~K}$, type-I materials will carry a current limited to a thin surface sheath a few hundred angstroms deep, and the interior of these materials exhibits perfect diamagnetism. But at any temperature below $T_{c}$ when exposed to an applied magnetic field $\mathrm{H}_{c}(\mathrm{~T})$ exceeding a critical value (typically a few hundred gauss), the shielding breaks down and the conductor reverts abruptly to the normal, or nonsuperconducting, state. The small cross section of the currentcarrying regioa and the low critical field eliminates these materials as candidates for magnet construction.

In type-II materials, similar surface shielding currents occur below a certain field, but above that field value, it is energetically favorable for magnetic flux to penetrate into the bulk of the conductor, ziving rise to a rather complicated magnetic structure there. This process persists until penetration is complete at a considerably higher field value, again a function of temperature, whereupon the superconductivity is finally destruyed. In addition to being able to support superconductivity in the presence of high magnetic fields, the interior of type-II materials can contribute to the effective conductor cross section. In so-called hard type 
II superconductors a very high bulk current capacity is realized by various metallurgical steps. The significance of type-II materials in magnet applications depends on these two properties, their high field capaility and high current capacity. The parameters which characterize these conductors, namely field, current, and temperatuse, are interrelated and must all be below certain critical values for the superconducting state to exist. For a given temperature and field, for instance, the conductor has a definite critical current $I_{c}(T, H)$; this current value generally varies inversely with temperature or field.

Although type-II superconductors were tested as early as 1925, and a few superconducting magnets were constructed in the late 1950's, the decisive breakthrough awaited the announcement by Kunzler et al. in 1961 of the very high field current capacity of the intermetallic compound $\mathrm{Nb}_{3} \mathrm{Sn}$, quickly followed by a rash of sma11 dc solenoids and the discovery of several other promising superconducting materials. ${ }^{2}$ Within a short period, NbZr, the first high field superconductor to be produced in long lengths of wire, was supplanted by the more ductile alloy NbTi, which also has superior superconducting properties. Early conductors were typically in the form of multistrand cables of twisted superconductor and copper strands impregnated with indium (1965), and later, composite conductors of filaments in a copper matrix became available (1967). The original "hard" superconductor, $\mathrm{Nb}_{3} \mathrm{Sn}$, possesses even higher critical field, current density and temperature, but at first its extremely brittle nature prevented it from being extensively used. In its early application,coils were wound with pure $\mathrm{Nb}$ and $\mathrm{Sn}$ in a suitable form and then heat treated or reacted to form the compound in an irretrievable coil. This technique quickly became obsolete (though it has been revived very recently with the advent of filamentary $\mathrm{Nb}_{3} \mathrm{Sn}$ ) when flexible $\mathrm{Nb}_{3} \mathrm{Sn}$ conductors became available in ribbon form, as very thin layers of superconductor on a strong and relatively thick substrate, produced by a vapor deposition or diffusion process.

Early superconducting magnets were plagued by unstable performance, characterized by "degradation" (failure to reach the current or field expected from tests on short samples of the conductor) and "training" (diminishing degradation after each successive transition to the normal state). This behavior was attributed to the process of "flux jumping", or sudden discontinuous field 
changes accompanied by rapid heating as flux penetrates the conductor. Fiux jumping occurs predominantly at low fields. Only gradually did it become clear that it is intimately related to the so-called pinning strength which plays a fundamental role in hard type-II superconductors and, consequently, is p-oportional to the critical current density of the material, which in turn varies inversely with field strength. However, decreasing the critical current density would defeat the objective of superconducting magnet designs, i.e., to achieve the highest possible current or field. It has been found more practical to manipulate two other properties to control or stabilize the conductor against flux jumping: its thermal environment and the conductor size.

The first approach led to the development of "fully stabilized" or "cryogenically stable" conductors. They consist of superconduct ors in close thermal and mechanical contact with sufficient normai metal of high electrical conductivity (usuilly copper) to smooth out local hot spots and to ensure an alternate current path during periods of instability, thereby preventing premature quenches of the magnet. Examples of such conductors are the tape configurations of $\mathrm{Nb}_{3} \mathrm{Sn}$ plated with silver or high purity copper for stabilization and supported by a stainless steel substrate for mechanical strength, and composites of NbTi strands in a copper matrix. Fully stabilized conductors are essential for very large devices, such as bubble chamber magnets, but their low overall current density makes them unsuitable in more compact high field magnets, for example, bending and focusing magnets for accelerators.

The subsequent quest for flux junp stable conductors with iittle or no additional stabilizing material, and attempts to reduce alternating current power losses which are also characteristic of hard superconductors, led to the recognition of several other stability criteria. For "adiabatic" or "enthalpy" stabilization, the superconductor is subdivided into many fine filaments, each of a size such that the enthalpy of the superconductor itself is sufficient for stabilization, or such that the energy dissipated during an adiabatic fiux jump can be absorbed by the materiai itself with a negligible rise in temperature. The principle of "dynamic" stabilization is to combine the superconductor with a small amount of pure metal to slow down the motion of flux ind allow time for the heat to escape. These independent criteria pointed the way to "intrinsically" stable multifilamentary conductors in the form of many superconducting filaments, each sufficiently 
small to ensure adiabatic stability, embedded in a high conductivity matrix of normal metal and twisted or transposed to minimize losses under pulsed conditions. 3 The necessity of twisting the filaments arises from the fact that because tiney are assembled ial a conducting matrix they will be electrically coupled in a changing magnetic field. Consequently, they do not behave as individual filaments unless they are given an axial twist, which effectively decouples them from each other.

Intrinsically stable conductors, introduced in 1968, have been commercially available in increasingly sophisticated form over the last few years. Presently, the superconductor is restricted to the ductile alloy NbTi, although prospects for filamentary conductors of $\mathrm{Nb}_{3} \mathrm{Sn}$ and the similarly brittle compound $\mathrm{V}_{3} \mathrm{Ga}$ in commercial quantities are not very good, promising operation at considerably higher fields and temperatures.

\section{Early Superconducting Magnets at BNL}

The earliest development proyram established by the Laboratory for the purpose of exploiting the potentials of superconducting magnets in high energy physics applications dates from 1962,4 one year after Kunzler's announcement. From the start, and for a period of some years, it concentrated on the use of $\mathrm{Nb}_{3} \mathrm{Sn}$ conductors to take advantage of their superior properties over other superconductors available at the time, in spite of the fact that their high pinning strength makes them intrinsically very unstable。 Albeit a modest beginning, the prograin bore fruit in a remarkably short time. Several of the aforementioned stabilizing techniques were pioneered and at once incorporated in a succession of early compact solenoids and Helmholtz coils.

\subsection{High Field Solenoid}

Typical of these magnets, and an early example was a $112 \mathrm{kG}$ solenoid ${ }^{5}$ constructed in 1964, (shown in Fig. 1). Designed in four concentric sections, each separately enorgized, it contained a total of 2600 meters of superconductors in the form of $\mathrm{Nb}_{3} \mathrm{Sn}$ coated stainless steel ribbon. The inner and outer diameters were $3.2 \mathrm{~cm}$ and $12.7 \mathrm{~cm}$, respectively, and the coil was $6.4 \mathrm{~cm}$ long. The four sections, starting with the outermost, carried currents of $60,85,105$ and 78 amperes, equivalent to an overall current density of $2.7 \times 10^{4} \mathrm{~A} / \mathrm{cm}^{2}$ 。 


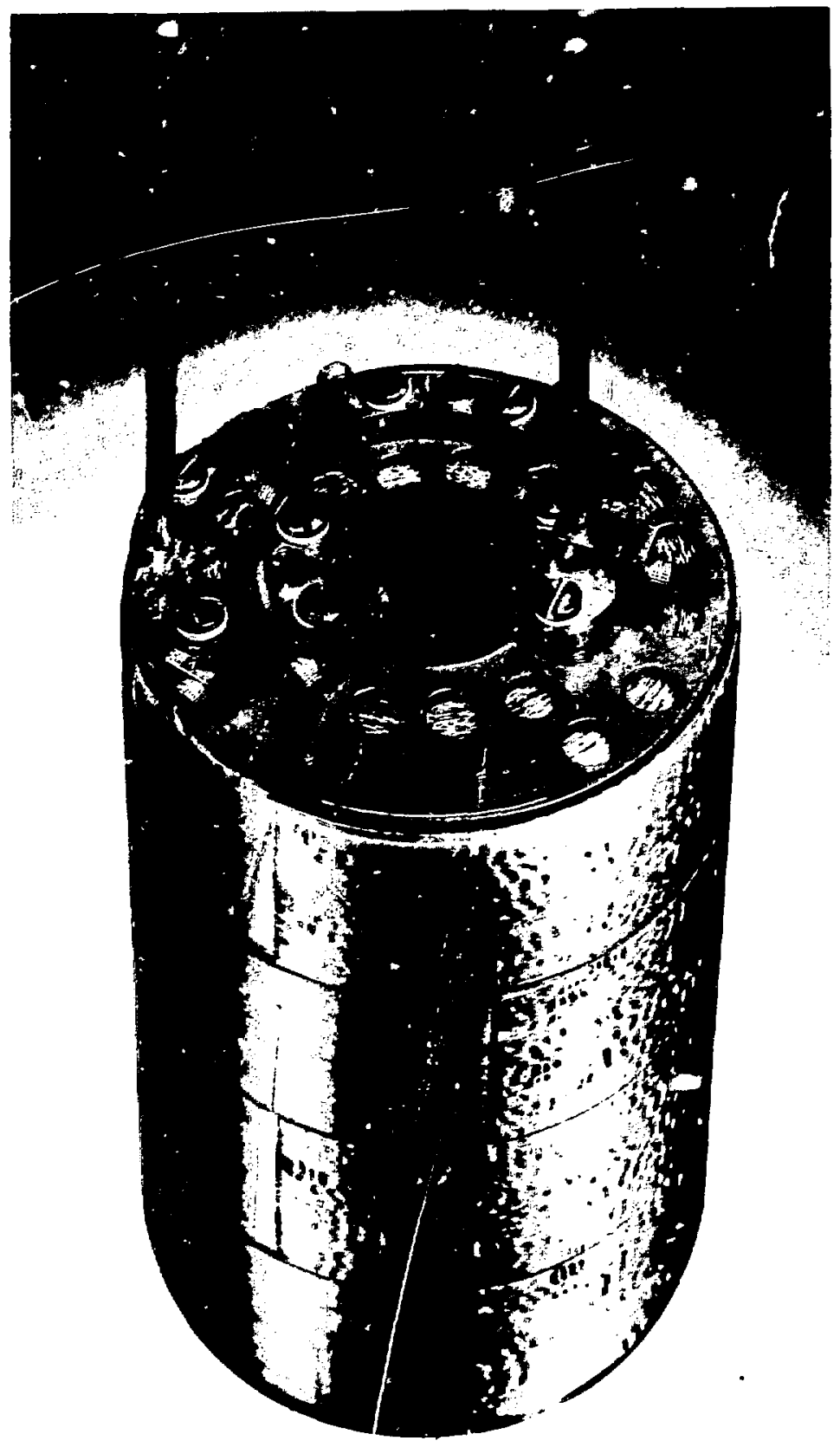

Figure 1. An early solenoid producing $112 \mathrm{kG}$. 
Several features of this early coil are noteworthy. As was pointed out, most flux jumps responsible for degradation occur at low fields. For this reason, the solenoid was constructed from several sections, taking advantage of the concept of "field stabilization", "whereby the field of the outer sections negates the low field regions from the inner coils. In this way, a large portion of the magnet operates at the maximum possible current, and the magnet current density is not limited by the short sample current of the high field section which may be less than the normal degraded current in the outer layer.

Anodized aluminum foil was used for layer-to-layer insulation. This had several stabilizing effects. First, it provided improved cooling of the interior coil sections by thermal conduction. Secondly, it provided dynamic stabilizabion by "eddy current damping"-that is, eddy currents induced in the foils increased the tine scale of Elux jumps, leading to lower maximum temperature during a disturbance. Copper shorting strips were placed across each layer to ensure that all turns were connected by a low resistance path. This lengthened the quenching time and thereby prevented excessive voltage buildup and arcing during the transition.

Yet another stabilizing technique discovered at BNL during the early phase of this work was the utilization of superfluid helium, by pumping the liquid helium bath. ${ }^{7}$ The improved coil stability realized by operating below the "lambda point" (2.2 K) depends on the increased thermal conductivity and viscosity of helium in the superfluid state. In addition, however, substantially enhanced performance was noted for coils which are not degraded at $4.2 \mathrm{~K}$. This effect was shown due to the increase in short sample critical current ac the lower temperatures.

\subsection{Solenoid for $\Xi^{-}$Experiment}

A good example of the application of superconducting magnets in specific experiments where the use of conventional magnets is precluded was an experiment conducted during 1967-68 at BNL to determine the magnetic moment of the short-lived negative Xi particle ( $\left.\Xi^{-}\right) .8$ Indeed, this was the first high erergy physics experiment to utilize superconducting magnets. It is illustrated schematically in Fig. 2. The $\Xi^{-}$hyperons were created during the interaction of $k^{-}$ mesons from the AGS with the protons in a target of solid hydrogen; after passing through the magnetic field of a superconducting solenoid," they decayed and the products were observed in a spark chamber behind the magnet. The 


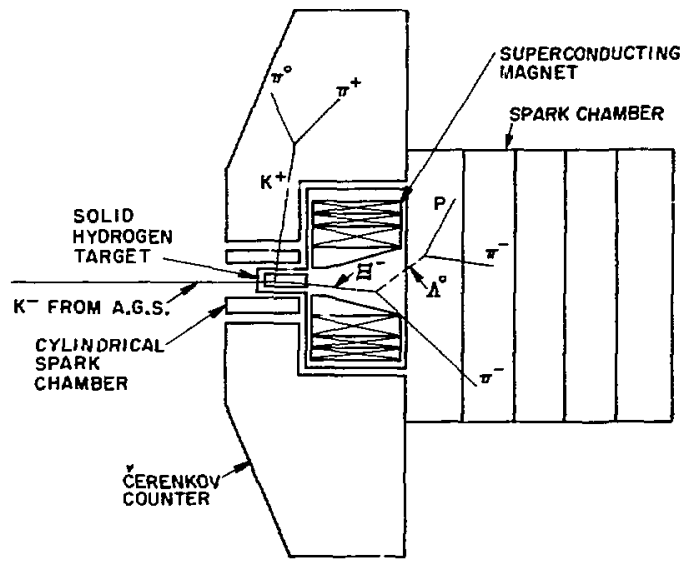

Figure 2. Schematic Diagram of $\bar{\Xi}^{-}$experiment. 
initial direction of the magnetic moment of the $\Xi^{-}$was defined by the various particles observed in cylindrical detectors surrounding the target. From the amount of precession of the decay distribution as a function of the magnetic field, and the field-distance integral along the flight path, the magnetic moment of the particle could be deduced.

In order to obtain the highest possible resolution, the anticipated value of the magnetic moment dictated a maximum field-distance product of $10^{6}$ gauss $-\mathrm{cm}$. Since the average distance travellea by the $\equiv$ before decay was on $1 \mathrm{y} 10 \mathrm{~cm}$, a field strength of at least $100 \mathrm{~kg}$ was required, aliminating conventional magnets.

The solenoid consisted of four concentric sections, clearly seen in Fig. 3. The inner section had a conical bore of half angle $8^{\circ}$ (the production angle of the $\Xi^{-}$particle), and diameter stween 3.8 and $6.6 \mathrm{~cm}$. The outer dianeter of the magnet was $18.2 \mathrm{~cm}$, and it was $10.4 \mathrm{~cm} 10 \mathrm{ng}$. Vápor. deposited $\mathrm{Nb}_{3} \mathrm{Sn}$ ribbon was used for the conductor. The inner two sections were stabilized by anodized aluminum foil, and the outer ones by Mylar-copperMylar foil. Copper shorting strips were again provided across each layer。

This solenoid produced a field of $125 \mathrm{kG}$. It was equipped with a thermal switch across the current leads by which they could be short-circuited for operation in the "persistent" mode. Liquid helium was supplied from a 3 watt collins liquefier in a closed circuit helium system, with an automatic sensor maintaining a constant liquid level. A total of $8.9 \times 10^{5}$ pictures were taken with the magnet in operation during the course of this experiment, including $1.7 \times 10^{4}$ possible $\equiv$ events.

\subsection{Other Special Purpose Coils and Devices}

of the many other small-bore high field coils in the 50-100 kG range constructed at BNL during the course of this paiticular ongoing program, designed for short sample measurements, ac superconductü loss determinations, or various experimental applications, severa! essentially identical $100 \mathrm{kG}$ Helmholtz or "split paini" coils still in use may be singled out for mention. They aie worild from $\mathrm{Nb}_{3} \mathrm{Sn}$ tape with the usual aluminum interlayer foil and copper shorting strips, and have a bore of $3.8 \mathrm{~cm}$. One of these was delivered to the National Bureau of Standards in 1968 for use in neutron diffraction experiments conducted jointly between the Bureau and the Naval Ordnance Laboratory. The other (Fig. 4) has seen intermittent operation for some years in a facility at the BNL High Flux Beam Reactor where it is used for similar neutron scattering experiments studying the dynamical and structural properties of solids. 


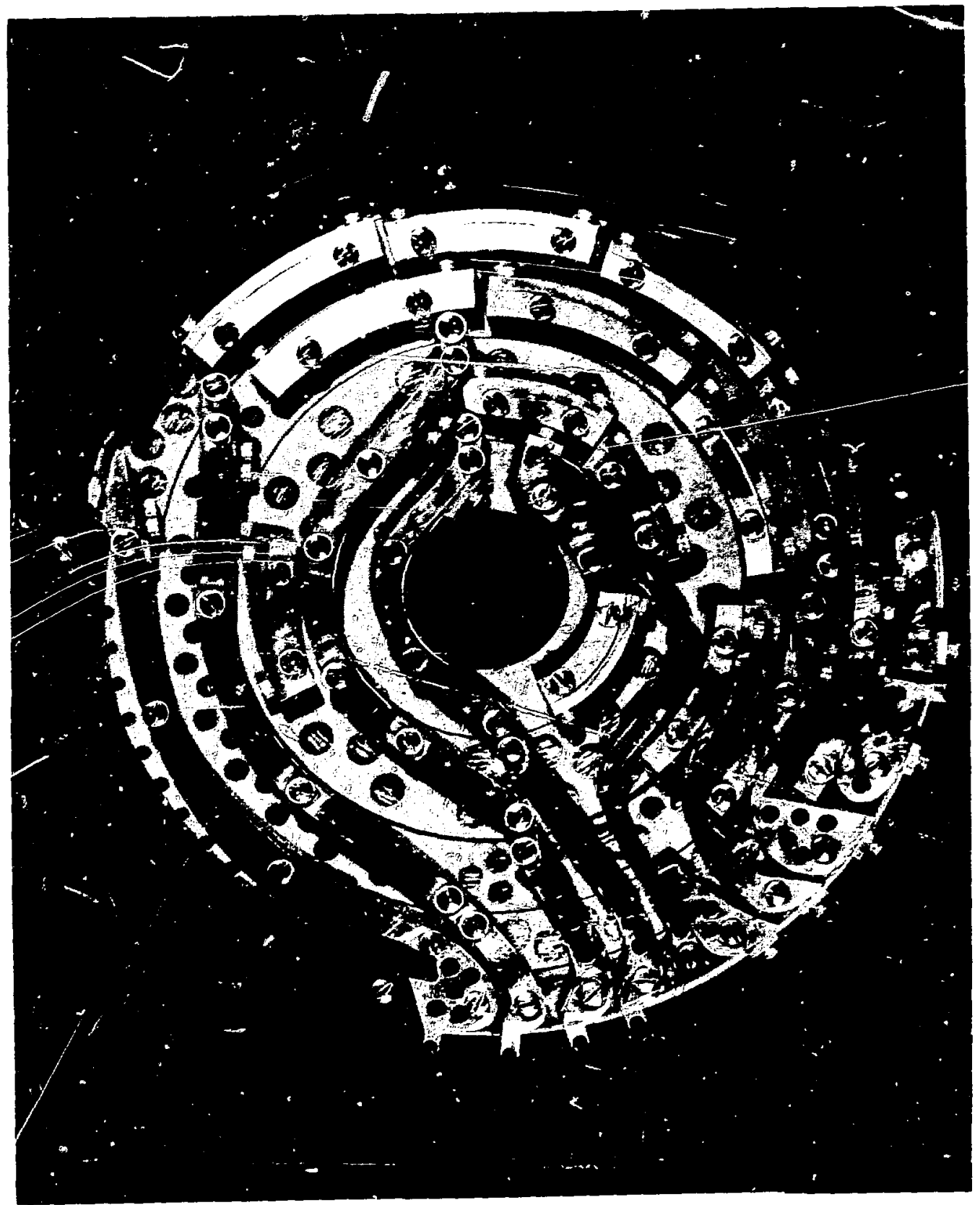

Figure 3. End view of solenoid for $\bar{E}^{-}$experiment, showing the four coil sections and the copper shorting bars. 


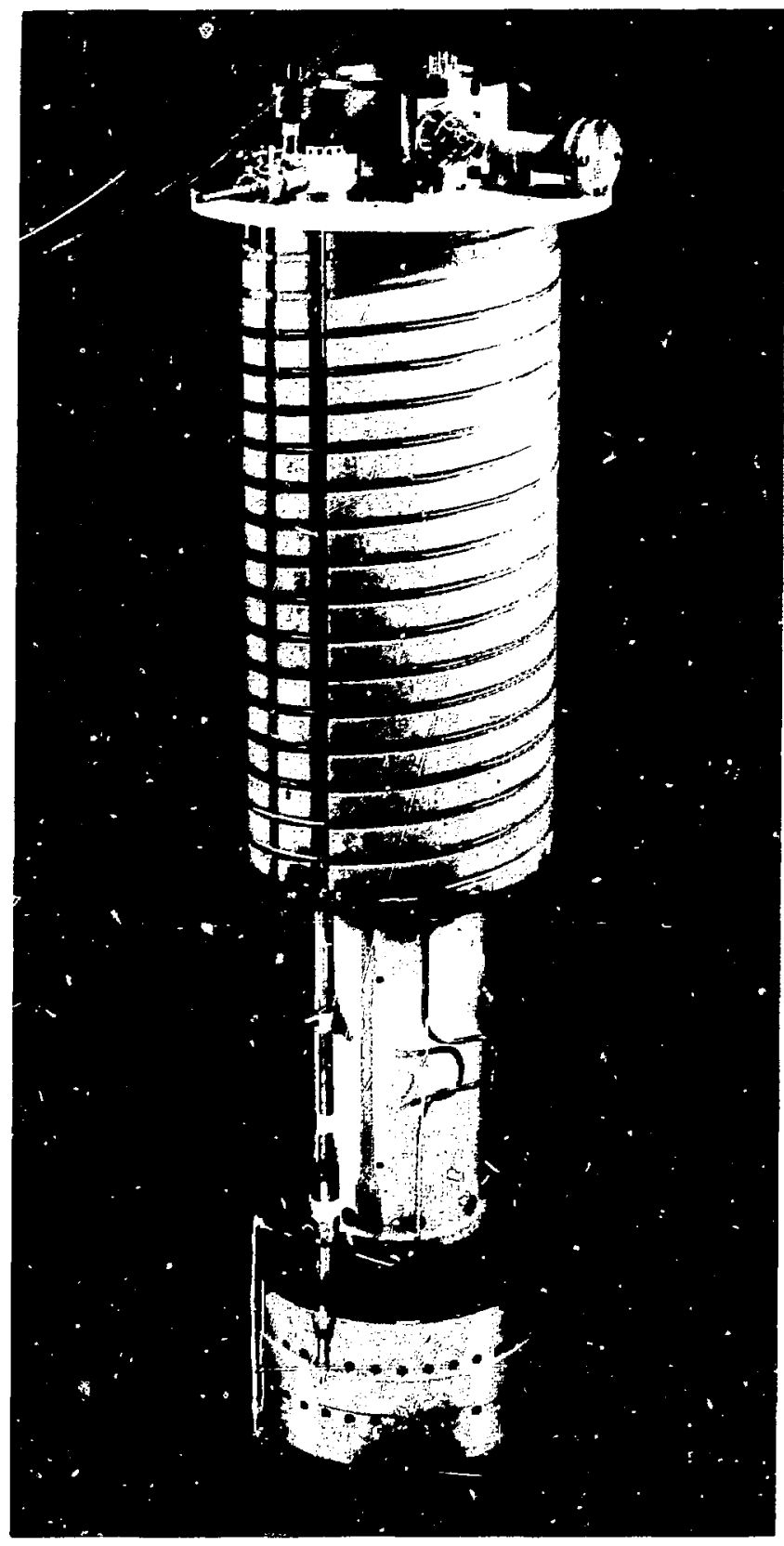

Figure 4, Helmholtz coil. for neutron scattering axperiments, ready for insertion into cryostat. 
It is operated in conjuntion with a variable temperature dewar; the spiitpair geometry provides $360^{\circ}$ access to the target volume. A newer solenoid constructed from NbTi multifilamentary wire is used at the National Magnet Laboratory in the determination of the magnetic moment of solid samples, under the influence of high pressure and high magnetic fields (up to $70 \mathrm{~kg}$ ). The fomogeniety of this magnet is of particular importance, and is approximately $0.02 \%$ over a $3 \mathrm{~cm}$ diameter spherical volume.

A novel application is a superconducting magnet devised recently in cooperation with Columbia-Presbyterian Medical Center, for guiding a manually propelled ferromagnetic-tipped catheter through blood vessels in the human head. Here a spinning solenoid is designed to produce an alternating field which will cause the moving catheter to flutter or vibrate slightly, therejy easing its passage along the tortuous path of the constricted vessels. 10

One of the major sources of heat in a dewar or cryostat is that of the current leads, and much effort has been expended at the Laboratory in developing efficient vapor-cooled leads, optimized for various current ranges. These leads typica!ly exhibit losses of the order of $1 \mathrm{~mW}$ per ampere. Concurrently, and in spite of the present availability of high performance commercial leads, the ancicipation of prolonged dc operation of various magnets in clused cycle systems, particularly rather inaccessible beam transport magnets, has prompted considerable "flux pump" development aimed at replacing the high current leads. At BNL, interest has concentrated on the development of we 11 regulated low loss pumps of the rectifier type. 11,12 They operate at $60 \mathrm{~Hz}$ and utilize magnetic switching, somewhat like a transformer-rectifier circuit. Such a pump was used to powe - the beam splitter magnet described below.

\section{Magnet for the BNL 7-Foot Bubble Chamber}

The magnets of the preceding section typify a class of compact high field superconducting coils. In small coils of this kind, full stabilization is ruled out as it compromises the current donsity, and stable performance must depend on other techniques. The extreme contrast is furnished by very large coils where fully stabilized conductors are essential for guaranteeing reliable performance and, due to the high stored energy involved, for magnet protection in case of a quench.

An example of large multi-megajoule superconducting magnets for high energy physics experimental purposes is the magnet for the BNL 7 foot bubble chamber. The largest air-core superconducting magnet anywhere at the time of 
construction, design of this magnet ${ }^{13}$ commenced in 1966 and it was initialiy energized two years later. Since then it has operated routinely with the bubble chamber for approximately $2000 \mathrm{~h}$ in the AGS experimental program.

The magnet is a Helmholtz or split-pair coil producing a central field of $30 \mathrm{kG}$ (the maximun field in the windings is $40.5 \mathrm{kG}$ ). This design allows entry of particle beams to the chamber, and access is further aided by the elimination of a massive iron yoke, common with other bubble chamber magnecs (Fig. 5). Each coil consists of 8 double pancakes of $2.4 \mathrm{~m}$ inner diameter and 2.7 m outer diameter, and each layer contains 44 turns or 348 continuous meters of conductor. The layers are supported and separated by radially slotted phenolic cooling spacers. In order to reduce the magnitude of the peak radial field component, which occurs at the coil ends and iimits the maximum attainable central field, the coil configuration is slightly modified here, and conductor lengths having the highest critical current chosen. The two coils are separated by a bridge structure and mounted in a single annular cryostat concentric with the vertical axis of the chamber. They are powered through 6000-ampere gas-cooled leads by a conventional power supply. The inductance of the magnet is $4 \mathrm{H}$, and it has a stored energy of $72 \mathrm{MJ}$. Protection is provided by an externa 1 "dump" resistor.

The conductor is a composite consisting of six NbTi cores in a $5 \mathrm{~cm} \times 0.2 \mathrm{~cm}$ OFHC copfer matrix. The copper-superconductor ratio is $6: 1$. Each turn contains four components: the fully stabilized superconductor, a Mylar turn-to-turn insulating strip, a stainless steel reinforcing strip, and a copper cooling channel spacer, in that order. In addition to the edge cooling, the cooling channels provide liquid contact with $75 \%$ of the conductor surface. At full field, the current density in a coil layer is $1.9 \times 10^{4} \mathrm{~A} / \mathrm{cm}^{2}$.

The dominating concern in the design of magnets of this type is the problem of stresses, electromagnetic and to lesser extent thermal. At $30 \mathrm{kG}$ and $6000 \mathrm{~A}$, there is a vertical attractive force of 1150 tons between the two coils of the BNL magnet. The symmetric radially outward hoop stress is shared between the stainless steel reinforcing strip and the conductor. In this design, the stabilizing copper is strained to its elastic limit, and while the stainless stee 1 does not support the major portion of the hoop force, it tends to restrain any possible "creep" in the conductor. At full field, the hoop stress is about $16000 \mathrm{psi}$ in the conductor and $37000 \mathrm{psi}$ in the reinforcing strip. 


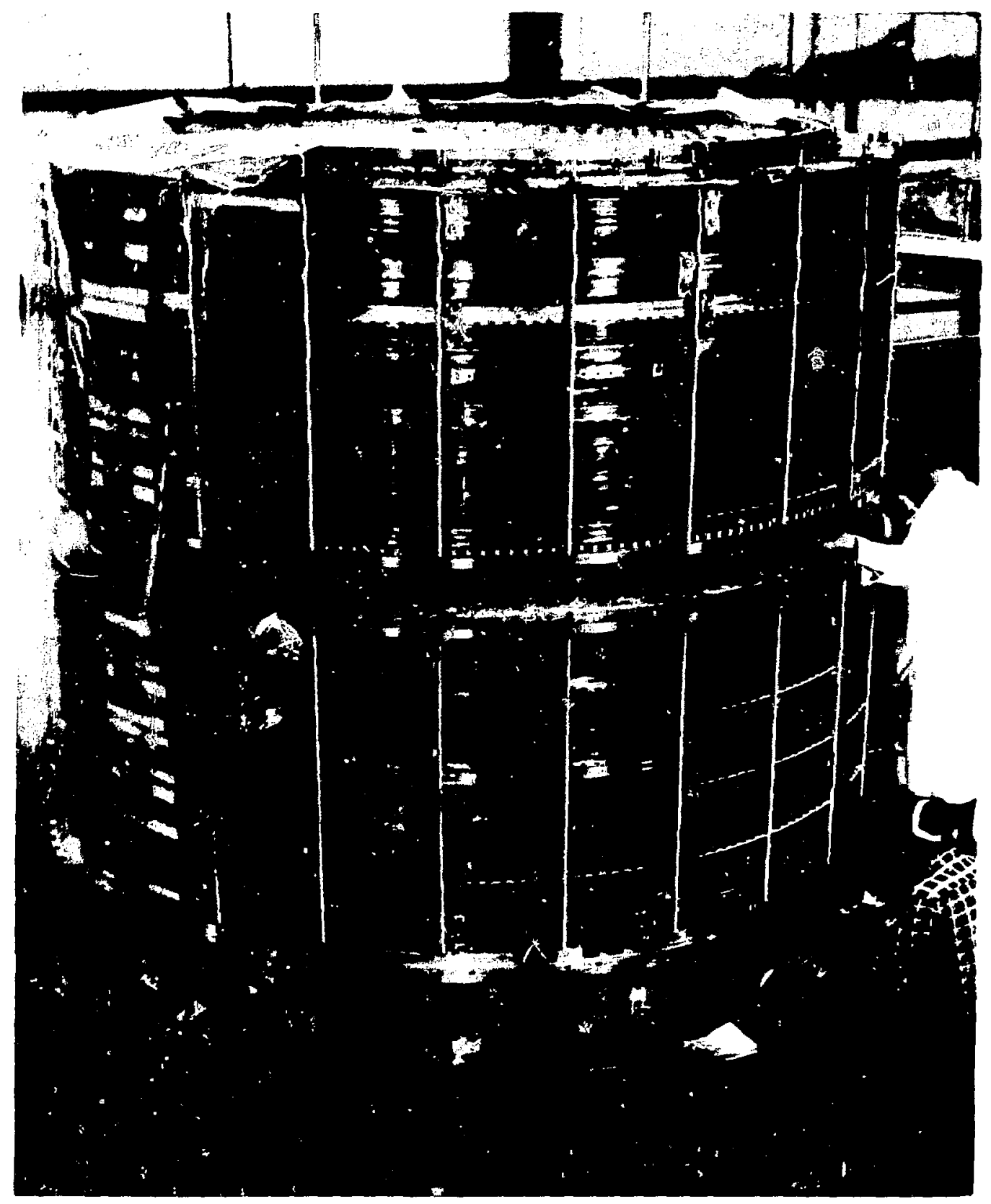

Flgure 5. Helmholtz coll for 7-ft bubble chamber. 
The dewar shares a common vacuurn tank with the bubble chamber and requires 3000 liters of helium with the magnet in place. The cooldown weight of magnet and dewar is approximately 53000 1bs, including 28000 1bs. of copper and 24000 lbs. of stainless steel. The refrigerator-liquefier is an ADL Model 2000 machine with capacity of $601 / \mathrm{h}$ as liquefier and 240 watt at $4.5 \mathrm{k}$ as a refrigerator.

\section{Beam Transport Magnets}

The diversion to external targets of high energy protons which are ejected from the AGS, as well as the channeling to experimental areas of secondary particles from targets within or external to the synchrotron ring, demands a multitude of bending and focusing inagnets. These "beam transport" components are major power consumers, requiring power about equivalent to the pulsed magnets of the AGS main ring itself. Superconducting magnets provide an attractive method of reducing this power while at the same time offering substantially higher fields and gradients. A number of superconducting dipoles, quadrupoles and septum magnets have been constructed in the Accelerator Department over tile past few years. The chronology of these devices reflects the evolving technology of superconducting magnets during the same period.

\subsection{Early Quadrupole Magnets}

The earliest versions of BNL superconducting dc beam transport magnets were contemporaries of the pioneering high field coils of sect1on 2 , and were developed in parallel with them. As was out lined above, relatively wide stabilized $\mathrm{Nb}_{3} \mathrm{Sn}$ conductors were exclusively pursued at first, because of their intrinsically superior superconducting properties, especially current density, over other conductors then available, and in spite of the irksome flux jump instabilities and diamagnetic field distortion effects associated with these conductors, which were not then fully appreciated. Essentially the same stabilizing techniques as those developed for solenoids were adopted for these saddle coils, particularly the method of co-winding with high purity aluminum or stainless steel tape, thereby providing eddy-current damping as well as good heat sinks, thermal paths and current shunts, all factors which contribute to enhanced dynamic stability. (Eventually, the need for these remedies would be lessened by the appearance of intrinsicaliy stable couductors.) A further difficulty faced in designing beam transport magnets and 
even more problematic in the case of pulsed accelerator magnets, relates to the necessity of supporting the conductors against electronagnetic forces to reduce conductor movement. While the force distribution in a solenoid is fairly straightforward to handle since it consists mainly of a symmetric radial hoop stress which can, as we have seen, be supported by the conductor itself in a tightly wound coil, the force distribution in saddle coils is more complex and conductor motion must be constrained by the magnet structure.

The first model magnets were severa? $20 \mathrm{~cm}$ long quadrupoles of the Panofsky type $^{14}$ with a rectangular aperture, constructed in $1965 .^{15}$ One of them is shown in Fig. 6. The coils were in the form of four mutually perpendicular current sheets of uniform current density, wound from copper stabilized $\mathrm{Nb}_{3} \mathrm{Sn}$ ribbon. They produced gradients of $10 \mathrm{kG} / \mathrm{cm}$ in a $3 \mathrm{~cm}$ aperture, corresponding to $4 \times 10^{4} \mathrm{~A} / \mathrm{cm}^{2}$ in the windings, but because of various drawbacks in the design, including an excessive peak-to-central field ratio and cumbersome end windings, this coil geometry as subsequently abandoned in favor of the "cos $2 \theta$ " or sector configuration. This design was pioneered at BNL. 16 It is a step function approxination to the ideal current density distribution required around the periphery of a circular aperture to produce a constant gradient (or more generally a field of any desired multipolarity) in that aperture. Here, the tape conductor is distributed in equal angular sections around the aperture and the current graded appropriately in the various sections by interleaving inert spacer turns, which may also contribute to stabilization and protection. (Dipoles based on this approach are treated in later sections.) A short quadrupole model of this type was tested in 1966. 17 It utilized anodized aluminum shims between the $\mathrm{Nb}_{3} \mathrm{Sn}$ conductors and produced $8.5 \mathrm{~kg} / \mathrm{cm}$ at 630 amperes in a $7.6 \mathrm{~cm}$ bore.

These efforts resulted in the construction of the first full size superconductin, beam transport elements at BNL during 1968-69 in the form of a quadrupole doublet, one member of which is shown in Fig. 7. Each magnet 18,19 was $60 \mathrm{~cm}$ long, with an aperture of $10 \mathrm{~cm}$, wourd from $1.27 \mathrm{~cm}$ wide $\mathrm{Nb}_{3} \mathrm{Sn}$ ribbon interleaved with stainless steel tape in the $\cos 2 \theta$ configuration. They produced gradients of $5.5 \mathrm{kG} / \mathrm{cm}$, corresponding to a peak field of $32 \mathrm{kG}$ at the walls. While the continuously changing demands of the AGS experimental program precluded their utilization at the time, they provided valuable experience and were the forerunners to a long line of saddle coil magnets for accelerator and beam transport application constructed at the Laboratory in the succeeding years. 


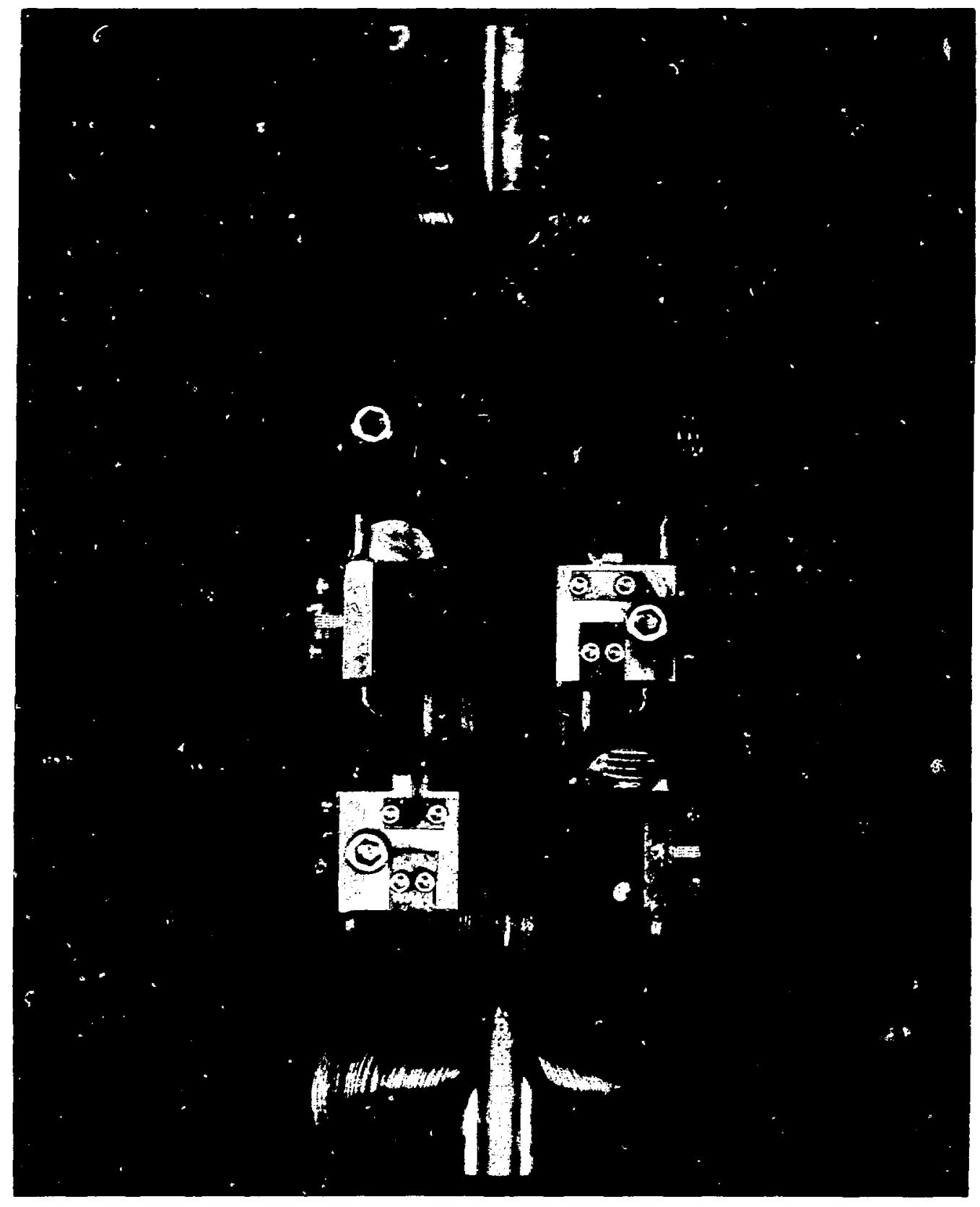

Figure 6. A small Panof sky type quadrupole. 


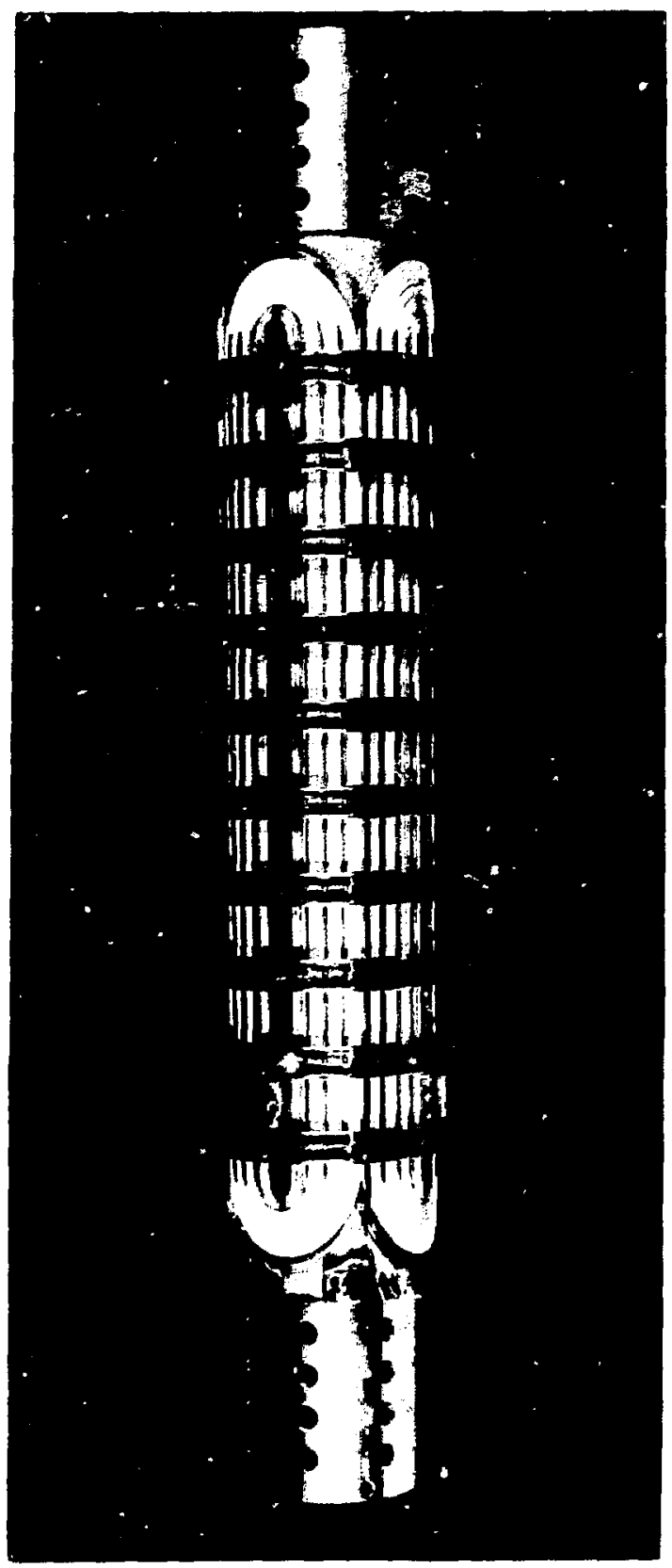

Figure 7. Quadrupole of the "cos $2 \theta$ " cype. 


\subsection{Bending Magnet for Secondary Beam}

A more recent sector-wound beam transport magnet using wide $\mathrm{Nb}_{3} \mathrm{Sn}$ tape, this dipole was one of a pair designed to produce a $4.8^{\circ}$ bend in an AGS secondary beam line. The development of new conductors incorporating intrinsically stable composites at the time it was designed rendered it prematurely obsolete, although its size and performance warrants notice and illustrates the potentials of high current density stabilized ribbon tape. The magnet was one meter long with a $9-\mathrm{cm}$ bore, designed for $42 \mathrm{~kg}$, and it was wound with $1.27 \mathrm{~cm}$ wije $\mathrm{Nb}_{3} \mathrm{Sn}$ tape in a $\cos \theta$ distribution utilizing stainiess steel and high conductivity aluminum spacers. The most important new feature of this design, and as will be seen, characteristic of essentially all modern high field superconducting accelerator or beam steering magnets, was the use of a close fitting concentric cylindrical iron return yoke or $f$ lux shield. 20,21 Such a yoke, it was realized, can play a most important role in many superconducting (i.e., air core) magnet applications, surprisingly at first. It enhances the central field produced by the coil alone (by a factor of approximately 1.6 in the present case), reduces the total stored energy as well as the field external to the magnet, and helps support the coils against the magnetic forces. This magnet was first tested in a vertical dewar during the summer of 1971, when it attained a central field of approximately $44 \mathrm{kG}$ (or 1200 amperes) on the first quench, corresponding to a current density in the windings of $50 \mathrm{kA} / \mathrm{cm}^{2}$.

\subsection{Beam Splitter Magnet}

This septum magnet 22,23 was the first operational beam transport magnet utilizing $\mathrm{Nb}_{3} \mathrm{Sn}$ solid tape conductor; it illustrates an application for which this conductor is particularly well suited. The magnet was designed as an element of a "beam splitter" system devised to increase the productivity of the slow extracted proton beam (SEB) from the AGS by allowing simultaneous sharing of this high intensity beam between two target stations. The beam is split so that protons from the same pulse impinge on the two targets by a system originally comprising a combination of electrostatic, magnetic, and superconducting units, in that order and separated by beam drift space. A steel shield was interposed between the last two units to shadow the superconducting septum in order to prevent heating of it as a result of beam interception in crse of faicure of either one or both of the upstream units.

The superconducting splitter is shown schematically in Fig. 8. It consists of two septum magnets facing each other. The fields inside these adjacent units are equal and opposite in polarity, allowing part of the beam 


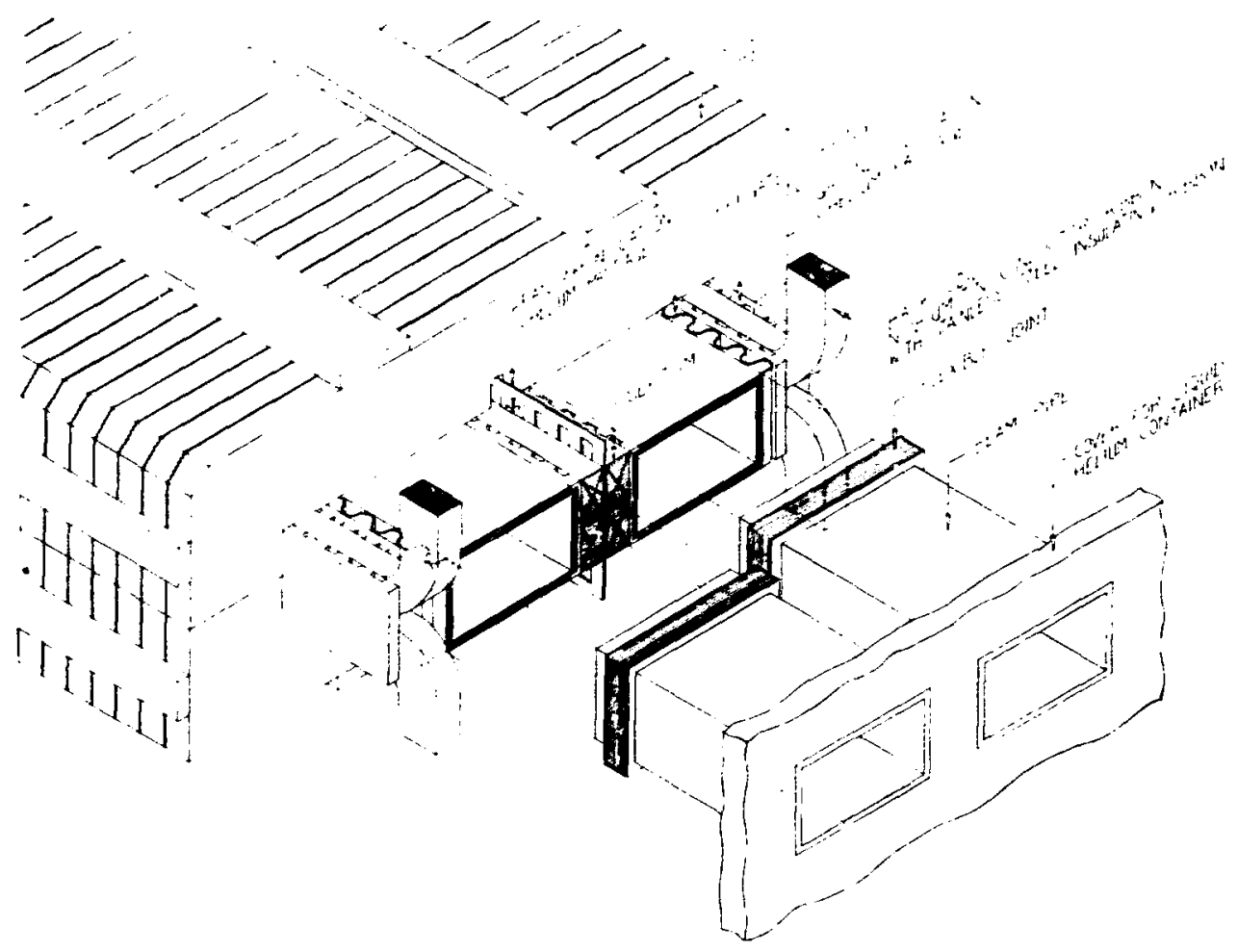

Figure 8. Schematic drawing of beam splitter magnet. 
to be deflected in one direction and part in the opposite direction. The magnetic forces in each aperture are also equal and opposite, so that no net force acts on the septum.

The separation of the two target stations and the available space in the direction of the beam line implied that the septum shruld be zapable of producing a total bend of $\pm 19 \mathrm{mrad}$ at a beam energy of $30 \mathrm{GeV}$. Since the magnetic length is $1.2 \mathrm{~m}$, a field of $15.5 \mathrm{~kg}$ was required. The coil design is of the conventional saddle type, witf the end windings supported by cast aluminum blocks. The deflecting strength of the upstream elements in the system limited the total septum thickness to $8.9 \mathrm{~mm}$, including vacuum chamber walls and insulation. This constraint and the expected heat leak into the cryostat dictated a septum of high current density, small cross section and large aspect ratio. It consists of two layers of $3 \mathrm{~mm}$ ride by $0.18 \mathrm{~mm}$ thick $\mathrm{Nb}_{3} \mathrm{Sn}$ ribbon, partially stabilized with copper. The current required to produce $15.5 \mathrm{kG}$ is 240 amperes, corresponding to a current density in the conductor of $45 \mathrm{kA} / \mathrm{cm}^{2}$. Insulation between turns is provided by stainless steel tape, and ground insulation (i.e., between the two coils and between the coils and the iron core) by anodized aluminum strips slotted for helium passage. The limitation on total septum thickness necessitated a cold vacuum chamber. The iron core consists of steel plates welded together with a small separation for cooling purposes.

The soundness of the mechanical design was examined in a $20 \mathrm{~cm}$ long full cross section model magnet, which reached a field of $28 \mathrm{kG}$, or $90 \mathrm{kA} / \mathrm{cm}^{2}$, approximately twice the design value. On completion of construction in the spring of 1973, the ful1 length magnet (Fig. 9) underwent a two month intermittent test without incident in a horizontal cryostat, powered by a Elux pump capable of 500 amperes. Magnetic measurements indicated that the fields in the two apertures are equal and opposite to a part in several thousand. It was subsequently installed in the SEB switchyard in the East Experimental Area of the AGS. Here it operated for a period although lack of adequate beam collimation and resultant high radiation levels at the time required it to be withdrawn from service later that year. An examination of the magnet is presently postponed due to a high level of induced radiation contamination; however, when feasible, it should contribute essential information concerniug the effects of radiation exposure on superconducting devices. (In this connection, the experience with the $8^{\circ}$ bending magnets is interesting, and is noted at the end of the rollowing section.) 


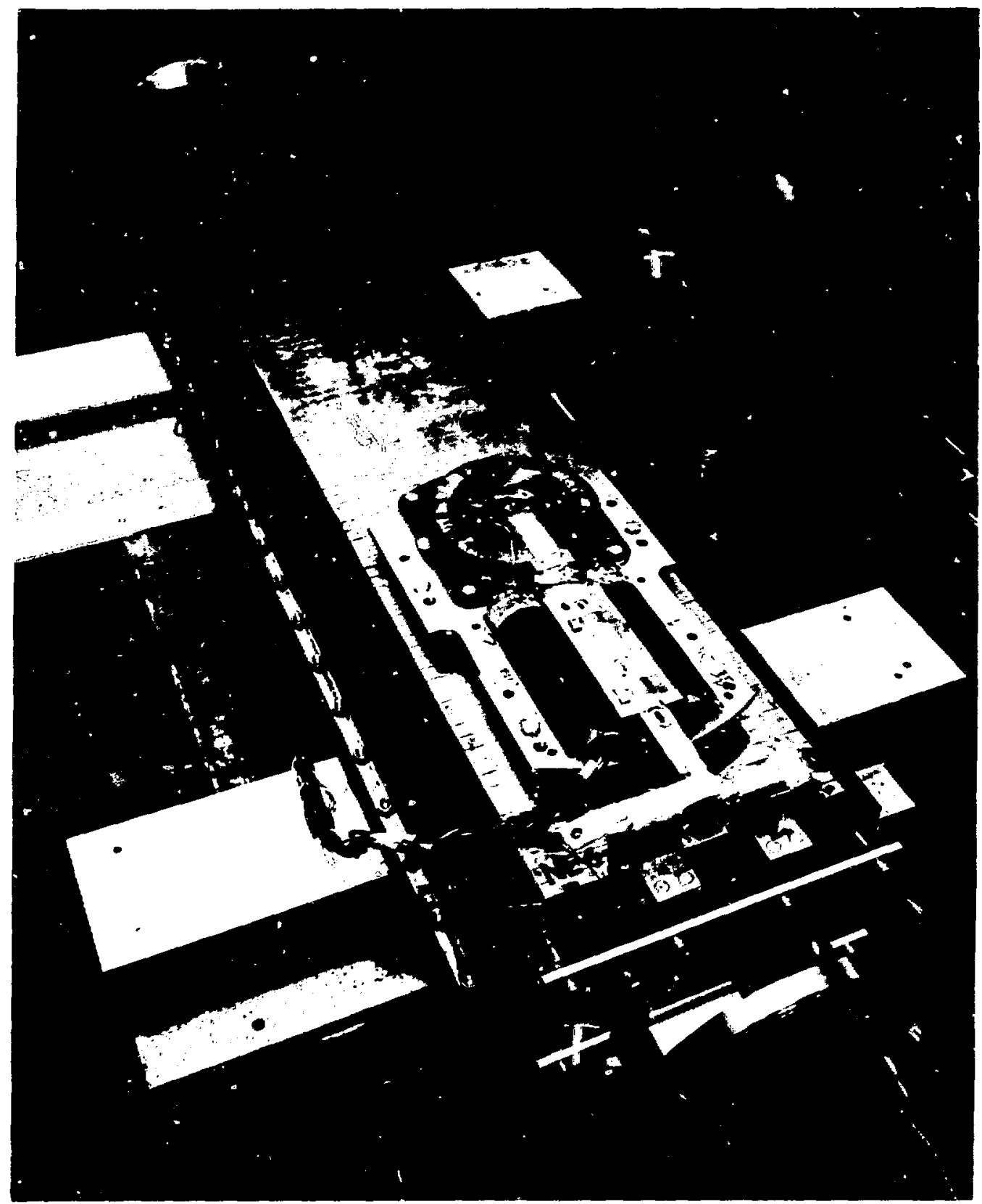

Figure 9. Botton view of beam splitter magnet. The flux pump can also be seen. 


\subsection{Dipoles in a Primary Proton Beam Lize}

The first superconducting primary beam transport system in routine operation serves to deflect by $8^{\circ}$ the extracted proton beam from the AGS to the 7-foot bubble chamber in the North Experimental Area Facility. It uses bending magnets of a desiga quite different from the cylindrical dipole or quadrupole configurations hitherto discussed. They are of the "window frame" 24 type more common for conventional beam steering magnets, consisting of an iron core with a rectangular aperture closely surrounding a set of vertical coils of rectangular cross section and are wound from newer copper stabilized NbTi composite conductor. The deflection of protons of momentum up to $30 \mathrm{GeV} / \mathrm{c}$ requires a peak field of $37 \mathrm{kG}$ and a magnetic length of 4 meters, provided by a pair of these magnets. They were installed in the early fall of 1973 and have performed very reliably since then.

The magnets 25,26 have a useful warm bore of $7.6 \mathrm{~cm}$ diameter. The coils define an almost square aperture approxıuately $10 \mathrm{~cm}$ wide, as shown in Fig. 10 . They are wound on a stainless steel form with 340 turns of NbTi conductor and are constrained without bonding material and free to contract azimuthally independent of the solid core of carbon steel. At low fields, the close proximity of this core gives a very uniform field and reduces the ampere turns required by a factor of about 2.5. As saturation sets in, the excitation requirements increase compared to those required for infinite permeability iron, and systematic field distortions require an auxiliary sextupole correction coil. A completed magnet is shown in Fig. 11 .

The main conductor is a Formvar insulated rectangular composite $2.9 \mathrm{~mm} \times$ $1.4 \mathrm{~mm}$ in size. It consists of $361 \mathrm{NbTi}$ cores, each 75 microns in diameter, embedded in a copper matrix with a copper to superconductor ratio of $1.25: 1$ and twisted with one turn per $2.54 \mathrm{~cm}$. The short sample current is 2400 amperes at $40 \mathrm{~kg}$. The conductor for the sextupole coil is a quarter-scale version of the main conductor. The excitation required by the correction coil commences at $20 \mathrm{kG}$ and increases approximately linearly to about five percent of the dipole ampere turns by $40 \mathrm{kG}$. At this field level, the dipole winding carries 1200 amperes and the sextupole winding 300 amperes, in both cases equivalent to a current density of about $30 \mathrm{kA} / \mathrm{cm}^{2}$. The inductance is $0.2 \mathrm{H}$ and the peak stored energy per magnet is $150 \mathrm{~kJ}$. Interlayer insulation and additional thermal and dynamic stabilization is obtained by vertical sheets of anodized aluminum of very high purity, grooved to provide helium channels over $50 \%$ of the conductor surface area. 


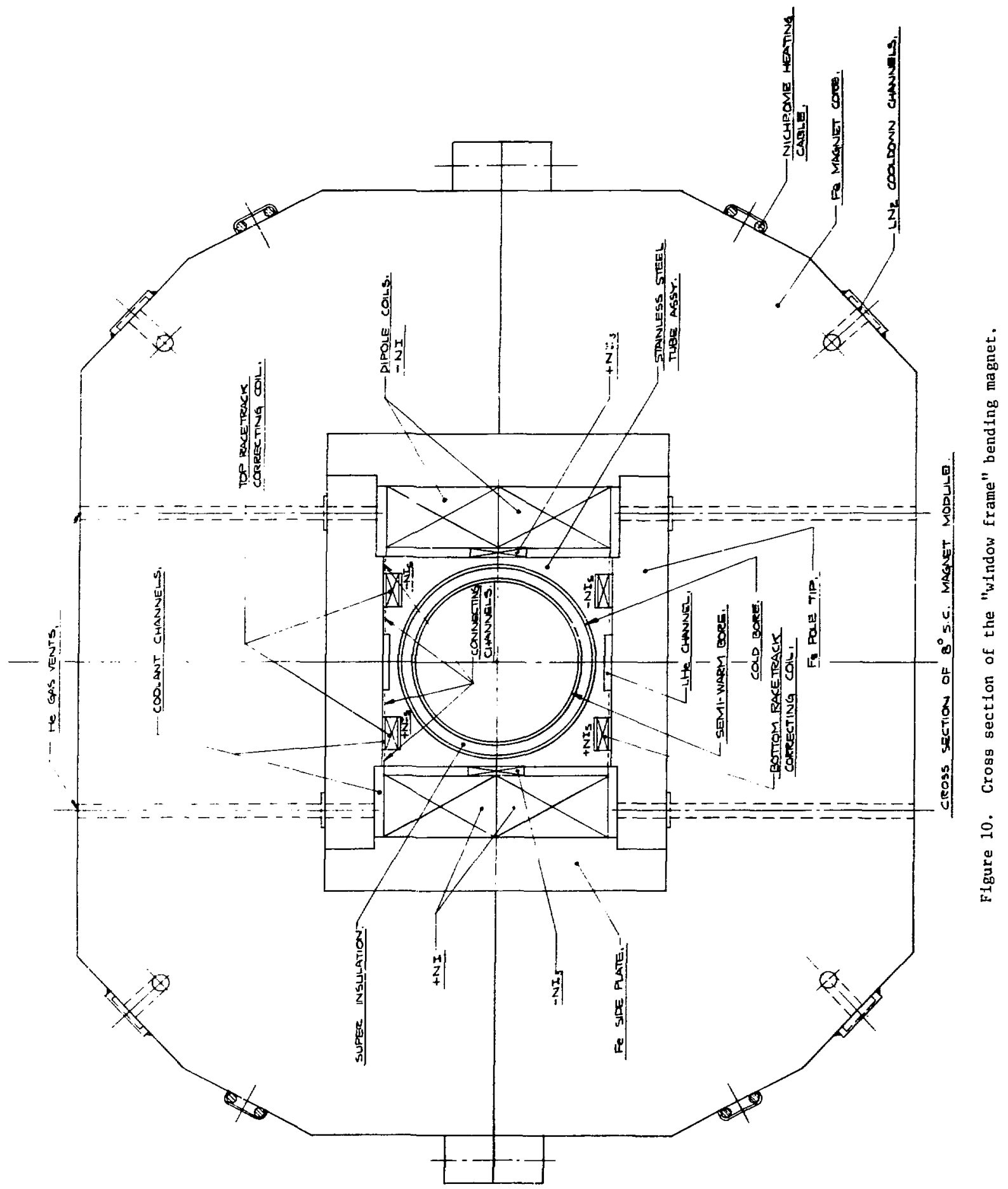




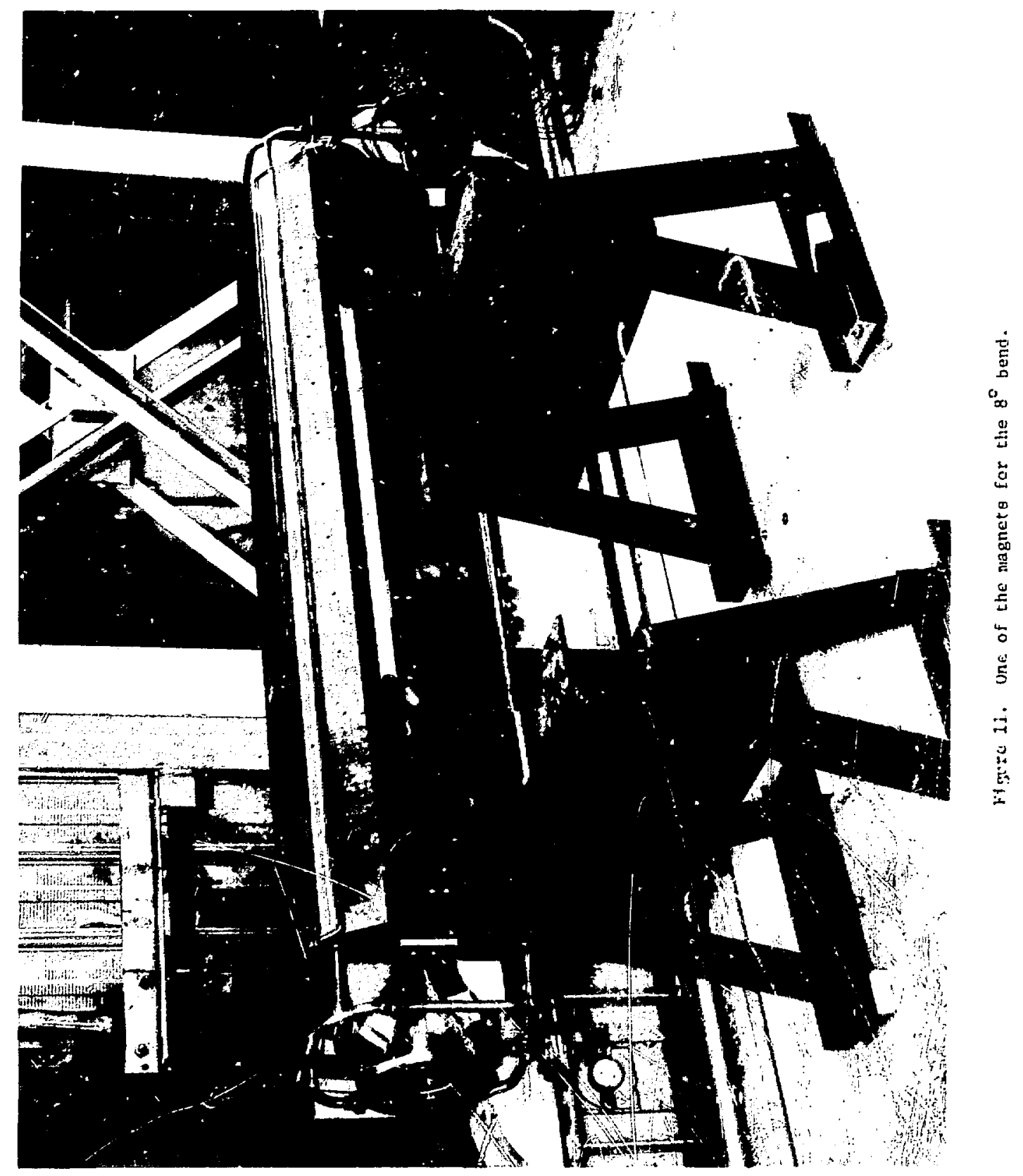


The magnets are mounted in two separate cryostats and operate in liquid heiium at $4.5 \mathrm{~K}$. They are powered in series with the electrical connections passing through the liquid to minimize the number of current leads and consequently, the refrigeration load, and are serviced by a 74 watt refrigeratorliquefier located outside the beam tunnel. The helium system is fully automated and includes provisions for gas recovery and storage for continuous operation during refrigerator maintenance. Figure 12 shows the two modules

Prior to cormissioning, the two magnets were extensively tested, during which they underwent repeated thermal and magnetic cycling, and preliminary field measurements were made. They exhibited very little training, both reaching a maximum field of approximately $44 \mathrm{kG}$ after on ly a few quenches. The harmonic field measurements verify that the field distributions in the two magnets are identical (and agree with computer calculations) to better than a part in $10^{4}$ over their useful aperture and over the entire field range. The absolute field precision is also very good; indeed, more careful field mappings on a $0.5 \mathrm{~m}$ Iong full cross section model of these magnets with short and long coils have indicated a field uniformity $\Delta B / B_{0}$ of $10^{-4}$ over essentially the full aperture ac low fields and over 6\%\% of the aperture at $38 \mathrm{kG}$, demonstrating that superconducting magnets of this type are capable of a ficld quality rivaling those attainable in the best conventional beam transport magnets。 27

The conservative design is reflected in the reliable performance and the stable and continuous cperation of the two units, ${ }^{28}$ traversed routinely by $6 \times 10^{12}$ protons per pulse with a beam power of $30 \mathrm{~kJ}$, and even unaffected by occasional intense bursts of radiation due to malfunctioning of other upstream components in the beam line, during which they have absorbed several hundred joules of energy in a few microseconds. The apparent tolerance to heating from relatively high radiation toses is of considerable significance for the manifold anticipated uses of superconducting devices in high radiation environments.

\section{Accelerator Magnets}

Design studies have been in progress in the Accelerator Department for some years with the objective a proton accelerator of very high energy, augmented by and taking advantage of an ongoing in-house superconducting magnet 


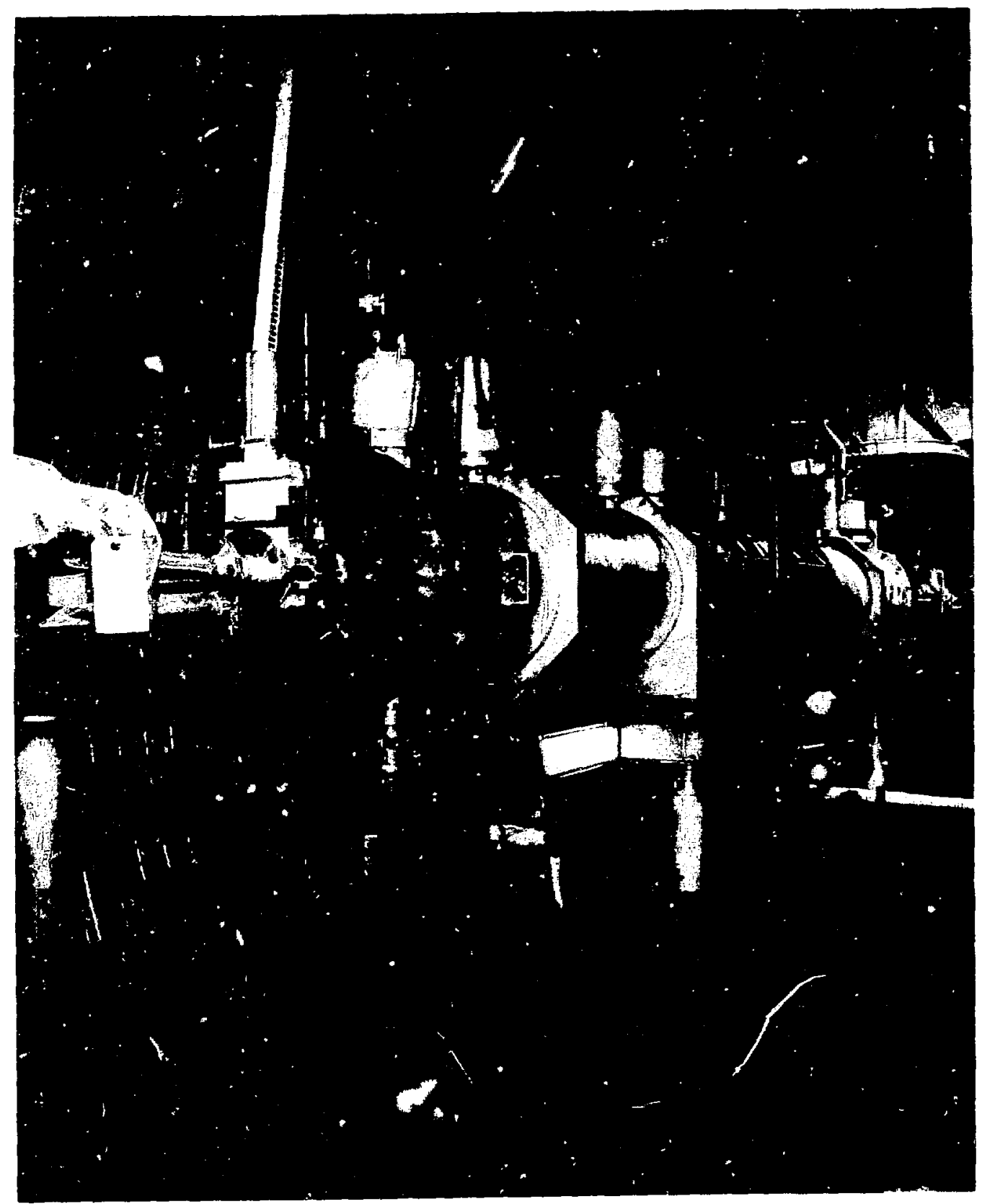

Ffgure 12. View of $8^{\circ}$ bending syster Installed in the beam IIne. 
development program to overcome econo:ical and technical limitations in conventional accelerator designs. Early studies concentrating on a proton synchrotron of approximately $2000 \mathrm{GeV}$, using pulsed superconducting magnets, were succeeded during $1969-70$ by a less ambitious scheme for a superconducting 112 GeV conversion of the AGS. In addition to upgrading the energy range of the present accelerator, this facility was visualized as a "pilot project" and ultimately as booster for a super-energy machine. However, as a consequence of the imninent completion of the 200-500 $\mathrm{GeV}$ synchrotron at NAL and the approval of a $300 \mathrm{GeV}$ European accelerator, coupled with the highly successful operation of the Intersecting Storage Ring (ISR) at CERN, these efforts were redirected during 1970-72, and focused on colliding beam systems in the energy range 200-2000 GeV. They culminated in a preliminary design for a $200 \mathrm{GeV}$ colliding beam facility using superconducting magnets termed Intersecting Storage Accelerator (ISA or ISABELLE). 30 colliding beam machines can generate high center-of-mass energies with relatively modest laboratory energies. They do not effectively produce secondary beams but they do provide an unparalleled opportunity for studying the reactions of the primary particles at the highest possible energies.

\section{1. $200 \mathrm{GeV}$ Intersecting Storage Accelerators}

Two colliding proton beams, each of $200 \mathrm{GeV}$ energy, would yield $400 \mathrm{GeV}$ center-of-mass energy, equivalent to protons of $86000 \mathrm{GeV}$ striking protons at rest. The ISA would extend the present (1974) center-of-mass energy range by almost a factor of ten and, equally significant, provide luminosities two orders of magnitude higher than those currently available. (Luminosity determines the rate at which a particular reaction takes place, the rate being the product of luminosity and the cross section for the reaction in question.) Its design is based on separate superconducting bending and focusing magnets distributed around two ring structures, one above the other and each 2700 meters long, in a four-fold symmetric configuration essentially that of a circle expanded by four long experimental straight sections, where the proton Deans intersect, and four straight service sections for injection, acceleration systems, etc. Proton pulses from the AGS would be stacked sequentially in each ring until 10 amperes of circulating current is accumulated, at which time the two beams can be slowly accelerated to full energy.

The long acceleration period ( 2 minutes) and "flat top" associated with this machine makes it a particularly attractive candidate for superconducting magnets. The $40 \mathrm{~kg}$ magnet design is tentatively (1974) based on commercially 
availabie NbTi superconducting wire. The eventual availability of filamentary conductors in commercial quantity of beta-tungsten type materials possessing superior superconducting properties appears very encouraging, however, as a result of research efforts at BNL and elsewhere, described briefly in a later section. These conductors would permit operation at aubstantially higher temperatures ( $8-9 \mathrm{~K}$ in contrast to 4-5 K for NbTi) with greatly reduced power consumption, and provide peak fields of $60 \mathrm{kG}$ or higher.

\subsection{Early Synchrotron Mode1 Marnets}

The superconducting synchrotron magnet development program at BNL has proceeded in several overlapping stages, its main initial impetus being provided by the availability of intrinsically stable conductors in 1968, in large measure as a result of the pioneering work at the Rutherford Laboratory, ${ }^{3}$ and culminating in the construction of a series of large ISA model dipoles during 1973--74, described in the next section.

The years 1968-69 were mainly devoted to ac loss measurements on multifilamentary composites of progressively finer filaments in smali solenoids, 31 and the development of suitable high-current conductors in the form of transposed braids containing several hundred of these wires. ${ }^{32}$ Methods for potting or impregnating them in magnet coils were also studied, ${ }^{33}$ since even magnets wound from intrinsically stable wire can suffer degradation and training if the coils are allowed to move under the influence of Lorentz forces.

An important advance was made in 1969 through the discovery at BNL of the exceptional stable magnet performance realized by bonding the individual twisted multifilamentary wires in a braid or cable with a secondary matrix of a soft metal, such as indium, through a series of metallurgical steps. 34 Such a conductor displays enhanced heat capacity and thermal conductivity, has excellent mechanical stability, and is quite insensitive to conductor motion. It may be thought of as an "intrinsically" stable cable analogous to the multifilamentary composite wire, where the transposed multicore wires in a soft metal matrix play the role of individual twisted filaments in a pure metal marrix. Howejer, the technique of metal filling results in considerable electrical coupling between the wires of the conductor for rapid field changes. Metallurgical treatment can reduce the coupling effects by increasing interwire resistance without impairing the superior stability of these materials. 
As the development of a satisfactory conductor progressed, the construction was initiated of a series of small $35 \mathrm{~cm}$ long pulsed model dipoles, designed to produce $40 \mathrm{kG}$ over a $5 \mathrm{~cm}$ aperture. ${ }^{35}$ Eight of these were assembled, one of which is shown in Fig. 13. They incorporated either insulated or metal impregnated conductors and were intended to explore various approaches to potting. The coils were of the $\cos \theta$ or sector type described earlier, consisting of a single layer of wide braided conductor distributed on a circle in discrete groups and graded into a current distribution varying azimuthally as the cosine of the angle from the median plane, by interleaving a spacer braid of stainless steel wires. In these magnets, the closely coupled concentric iron shield (seen in Fig. 13) contributes about $40 \%$ to the field. The wide transposed ribbon conductor assures efficient cooling in the helium bath. Moreover, since the "inert" spacer turns are extended around the magnet ends, the current density is graded axially as well as azimuthally, minimizing the final end shaping necessary to eliminate unwanted axial field harmonics. This approach, it is felt, is well suited for accelerator dipoles and quadrupoles, as it is readily adopted to mass production techniques with a high degree of accuracy. The design is also simply extended to several conductor layers for dipoles of substantially higher field.

An alternate dipole configuration explored extensively at BNL, also well suited for accelerator magnets, is based on the "window frame" approach. 36 Examples of beam transport magnets of this type are discussed in Section 4.

\subsection{ISA Model Dipoles}

Storage ring magnets differ from rapidly cycling synchrotron magnets in that their power losses are relatively unimportant, but tolerances on field uniformity on the other hand are much more severe due to the long lifetimes of the stored beams. During 1973-74, two larger "identical" model magnets designed specifically to meet the requirements of ISA were completed and tested.' Termed ISA I and ISA II, these dipoles are $90 \mathrm{~cm} \mathrm{long,} \mathrm{have} \mathrm{an}$ $8 \mathrm{~cm}$ diameter bore, and are designed to produce a central field of $40 \mathrm{kG}$. (ISA currently calls for $4.25 \mathrm{~m}$ long magnets with an aperture of $12 \mathrm{~cm}$.) They were intended to verify the expected field precision and for examination of the reproducibility from magnet to magnet. By subjecting them to continuous pulsing over an extended interval in a common cryostat, their long-term reliability could also be determined and cryogenic experience gained with a closed cycle refrigeration system. 


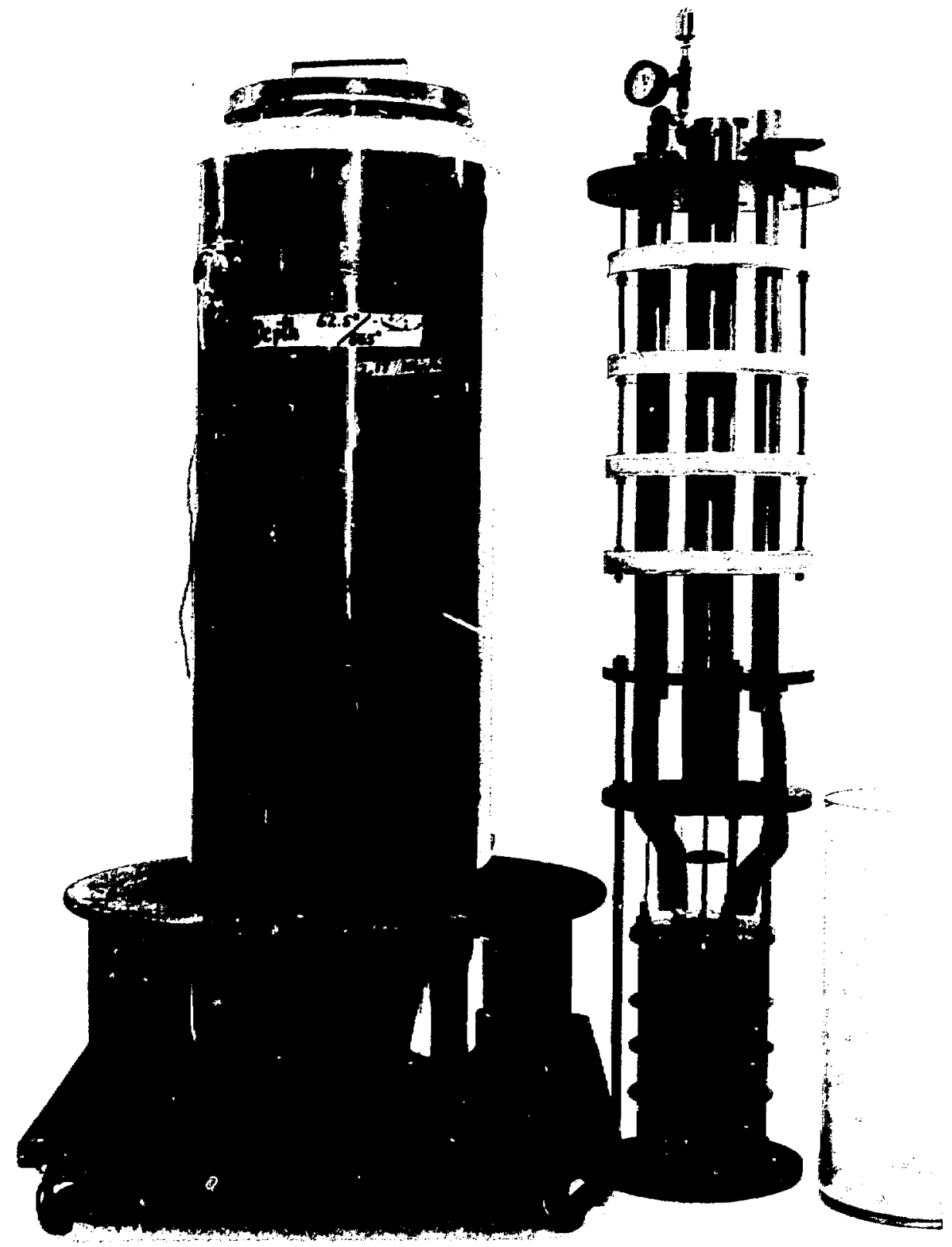

Figure 13. Model ac dipole, with laminated fron shield, shown with the test dewar and the calorimeter arsangement for ac loss measurements. 
The coil configuration is again of the cos $e$ type. It consists of 24 conductor blocks containing $2-\mathrm{cm}$ wide braid, positioned so as to minimize the lower Fourier harmonics in the field distribution, with the aid of a computer program called MAGFLD, ${ }^{38}$ and assembled in a precision mold. The coils are mounted in a laminated iron shield by a method ensuring that they are clamped firmly at all temperatures. A cross section of a magnet is shown in Fig. 14, and Fig. 15 shows one coil with the top half of the split iron shield removed. The conductor is braided from 186 twisted composite wires, $0.2 \mathrm{~mm}$ in diameter, each containing approximately 400 superconducting filaments of $7 \mu$ diameter. It is filled with an InTl alloy to assure the highest degree of stability. Small correction windings are incorporated in the design to correct for undesirable sextupole and decapole harmonics introduced by superconductor magnetization at low fields and iron saturation effects at high fields. They can be seen in Fig. 14.

Preliminary tests were made on each magnet mounted in an open vertical dewar. They reached the design current ( 3500 amperes) with no difficulty and exhibited remarkably little training. At this current, the overall current density in the windings is $30 \mathrm{kA} / \mathrm{cm}^{2}$. The maximum field attained was $45 \mathrm{kG}$. Extensive harmonic field measurements were carried out over the full field range during dc and pulsed operation using a set of measuring coils developed at BNL and designed to detect specific Fourier components. 39 At low rates of field change, these measurements were in good agreement vith calculated field distributions (the calculations, performed with the computer program GRACY, 40 take into account both superconductor magnetization and iron saturation) and consistent with estimated constructional tolerances. At faster field changes, the harmonics are altered somewhat by currents induced between the wires in the metal-stabilized braid.

After completion of these measurements, the two dipoles were mounted in series electrically in a common horizontal cryostat with room temperature bore for more precise field comparisons (Fig. 16) using a pair of computer controlled harmonic coils and a nuclear magnetic resonance system and for extensive magnetic and thermal cycling. 41 The field distributions appear to be identical to within a few parts in $10^{5}$. They then underwent a 3 month test program in the course of which they were subjected to approximately 5500 pulses, each current pulse of rise and fali duration characteristic of ISA but with a very short flat top, to simulate the expected lifetime of a storage accelerator in a fairly short time. During this sequence, 


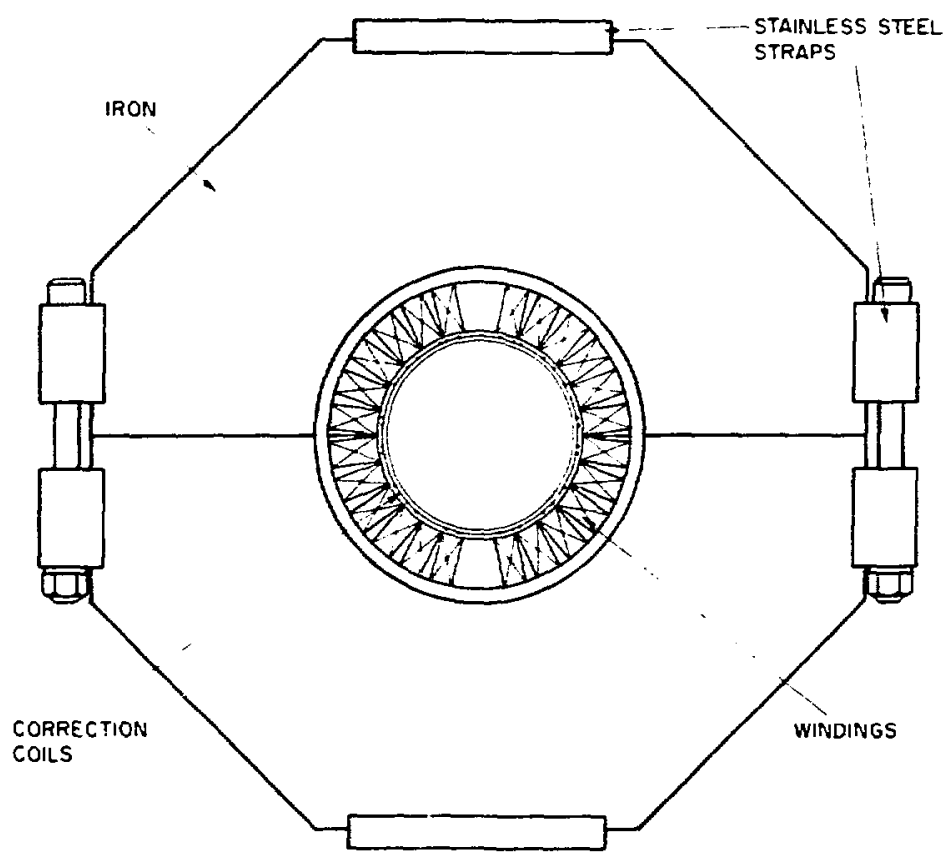

Figure 14. Cross section of ISA model dipole. 


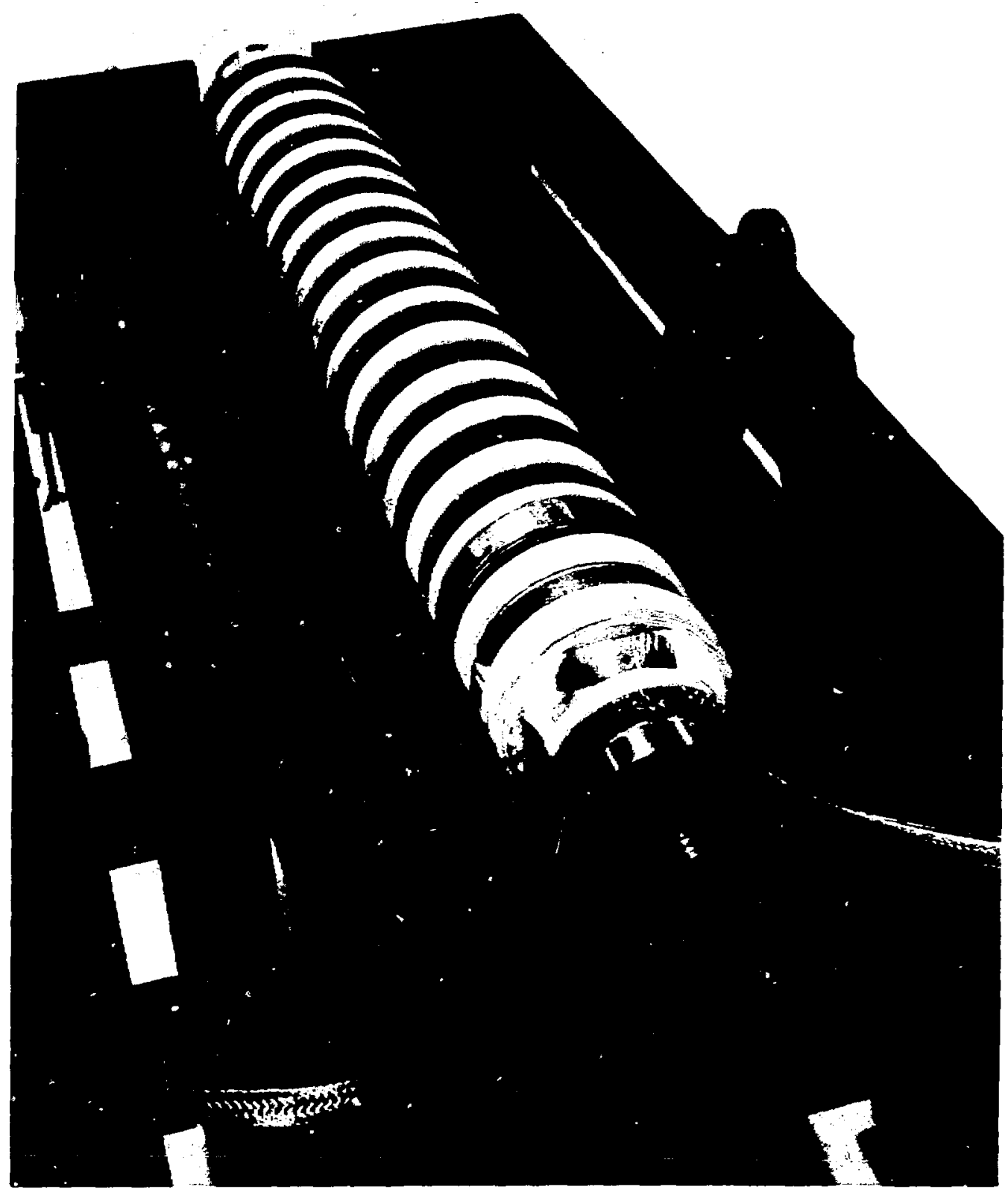

Figure 15. ISA model magnet with the top half of the Iron core removed. 


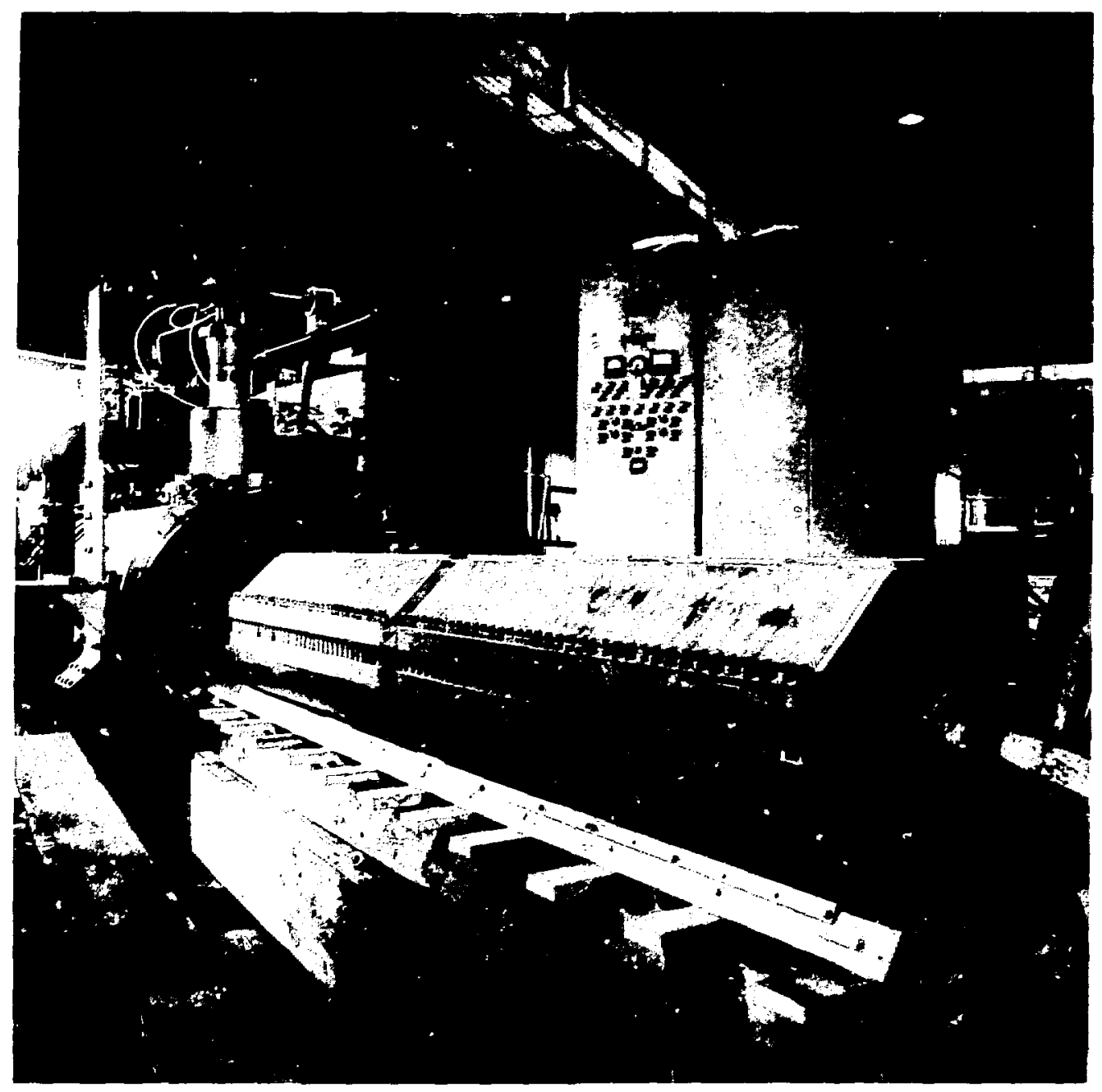

Figure 16. ISA I and II just prior to insertion in the horizontal cryostat. 
field measurements were periodically repeated and the magneis were also cycled to room temperature as well as deliberately quenched a number of times. No significant change in magnet performance was experienced from any of these effects, nor could any change in the field distributions be detected within the accuracy of the measurements (about $10^{-5} / \mathrm{cm}^{2}$ in the case of the sextupole field component).

Two further $90 \mathrm{~cm}$ long model dipoles are presently being assembled. The first of these, ISA III, uses a conductor braided from organically insulated wire, and in the second, ISA IV, the wires are insulated by a surface layer of copper-nickel. The main purpose here is to eliminate the dynamic effects associated with the conductor in ISA I and II without impairing its excellent stability. Note also that the magnet design allows the substitution of a conductor manufactured in essentially the same way from multifilamentary $\mathrm{Nb}_{3} \mathrm{Sn}$ wire when this material becomes available.

\section{New Superconductor Development.}

Almost all modern high field superconducting magnets utilize "intrinsically stable" conductors consisting of fine twisted superconducting filaments in a high conductivity normal metal matrix. They offer excellent stability and low losses under pulsed conditions. At present, the only superconductor available in this form is the ductile alloy NbTi. Various brittle materials classified as A-15 compounds, particularly $\mathrm{Nb}_{3} \mathrm{Sn}$ and $\mathrm{V}_{3} \mathrm{Ga}$, have higher critical temperatures, magnetic fields, and current densities but, because of their lack of ductility, are difficult to manufacture in multifilamentary form. However, recent developments in the area of superconducting materials now point to the feasibility of producing filamentary A-15 wires on a commercial scale. Brookhaven has participated vigorously in these efforts. The low ductility is circumented by delaying the formation of the superconducting compound until all extrusion and drawing steps have been completed. Billets of pure $\mathrm{Nb}$ or $\mathrm{V}$ rods embedded in a $\mathrm{Cu}-\mathrm{Sn}$ or $\mathrm{Cu}-\mathrm{Ga}$ bronze matrix are drawn down in much the same way as conventional NbTi in a copper billet. After drawing to final size, the wire is axially twisted and then heat treated, during which $\mathrm{Sn}$ or $\mathrm{Ga}$ from the bronze matrix diffuses into the core material to form filaments of $\mathrm{Nb}_{3} \mathrm{Sn}$ or $\mathrm{V}_{3} \mathrm{Ga} .^{42-44} \mathrm{~A}$ difficulty encountered in this process is the rapid work hardening of these bronzes, necessitating frequent annealing during the drawing process. A new process developed at BNL overcomes this problem. 45 In it $\mathrm{Nb}$ or $\mathrm{V}$ is first drawn 
down in a pure copper matrix. Afterward, this composite wire is coated with a layer of $\mathrm{Sn}$ or $\mathrm{Ga}$ by a dipping technique, and then heat treated in several steps to form the bronze matrix and compound, respectively, by diffusion. A microphotograph of a $\mathrm{Nb}_{3} \mathrm{Sn}$ composite wire made by this "external diffusion" technique is shown ir. Fig. 17.

A-15 composite samples have been produced with cricial current densities comparable or superior to those of commercial tape conductors. ${ }^{46}$ This work has clear implications for controlled thermonuclear research programs and possibly for the projected ISA facility. It has now advanced to the point where sufficient $\mathrm{Nb}_{3} \mathrm{Sn}$ conductor in a fully transposed braid configuration should be available shortly for the construction of a one-meter long dipole magnet designed to produce $60 \mathrm{kG}$ 。

Another important dividend of the Laboratory's superconducting materials research program has been the deveiopment of $\mathrm{Nb}_{3} \mathrm{Sn}$ tapes with low ac losses for power transmission as discussed in the next section, and the ongoing study of metallurgical factors which affect the performance of superconducting rf cavities, summarized in the section after that.

\section{Underground Power Transmission by Superconducting Cables}

An interdepartmental study group was organized at the Laboratory in 1971 to investigate the possibility of constructing high-capacity electrical power transmission cables using superconductors. It formed the nucleus for an extensive and continuing development program ${ }^{47}$ to design and test a practical underground transmission system. The approach taken is to apply supercondicting technology to an extension of the conventional high pressure oilfilled (HPOF) practice in the form of flexible superconducting cables pulled through a thermally insulated cryogenic envelope, with helium gas replacing the oil. Due to the high cost of conversion equipment, direct current cables have advantages only over long distances. It appears that the initial superconducting application will be to alternating current systems for relatively short runs, and where cables are required to be underground and the load exceeds the conventional capability. 


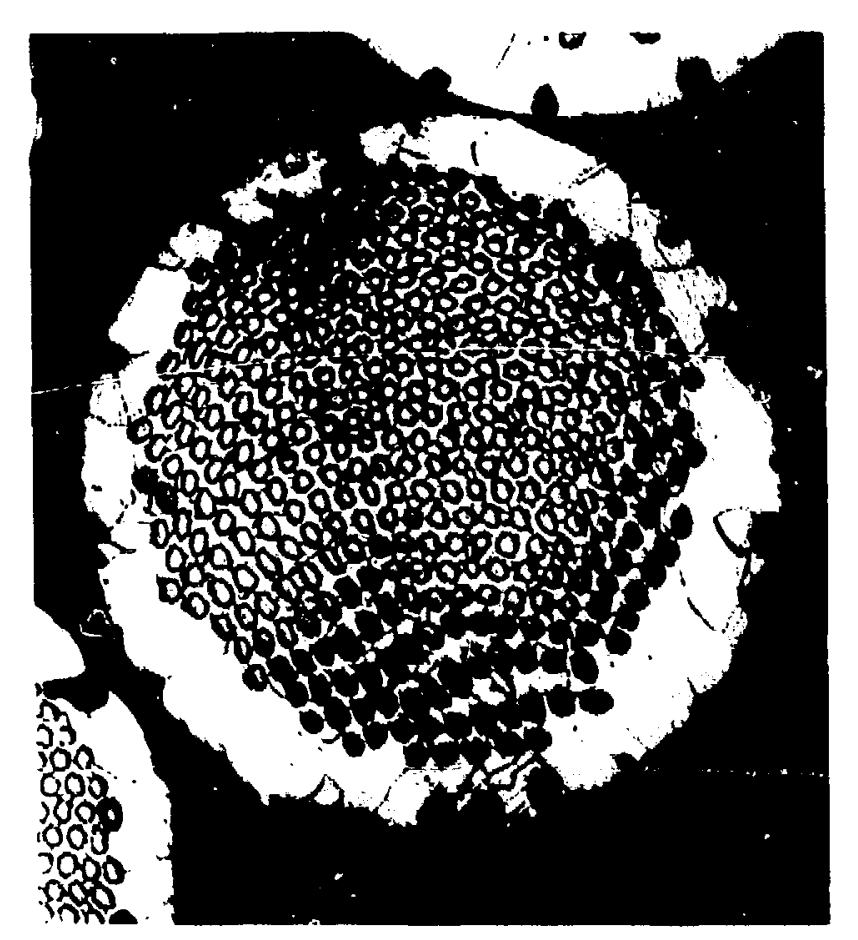

(a)

$$
50 \mu
$$

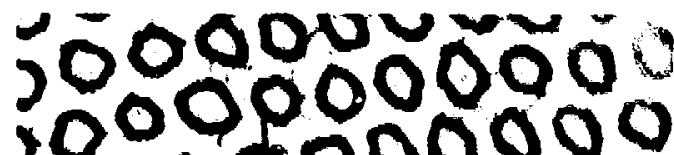

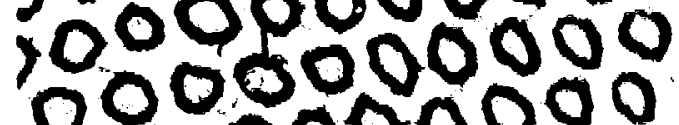

$$
\begin{aligned}
& 9000000000 \\
& \begin{array}{l}
1.0000000000 \\
0000000
\end{array} \\
& \text { 600000000 } \\
& 20000000 \\
& \begin{array}{l}
0.0000000 \\
000000
\end{array}
\end{aligned}
$$

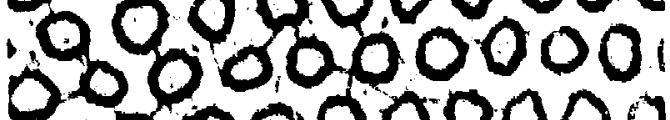

$$
\begin{aligned}
& \text { asogoOQOOO } \\
& 20000000 \\
& 20 \Rightarrow 000000
\end{aligned}
$$

(b)

$$
\stackrel{20 \mu}{1}
$$

Figure 17. Microphotograph of a $\mathrm{Nb}_{3} \mathrm{Sn}$ composite made by the external diffusion $\mathrm{Mb}_{3} \mathrm{sn}$ on the niobium cores, can be clearly seen in Figure $17 \mathrm{~b}$.
. 
Primary stress has been placed $J n$ developing a condurtor with acceptable losses at power frequencies. Niobium conductors have low losses al though their low critical temperature results in poor efficiency. The BNL design favors a flexible coaxial cable of $\mathrm{Nb}_{3} \mathrm{Sn}$ tape, ${ }^{48}$ due to its superior critical temperature and critical current densj.ty. Such a transmission line will have greater fault capacity and require less refrigeration than a line based on pure niobium. A method has been developed at BNL for substantially reducing the losses in $\mathrm{Nb}_{3} \mathrm{Sn}$ tapes; indeed, recent samples exhibit losses lower than those associated with the best commercially available tapes. 49 A scale model of a cable rated at $345 \mathrm{kV}$ is shown in Fig. 18 .

of all the components in a superionducting transmission line, the cryostat appears to be by far the most expensive. Siudies of flexible dewars are in progress, and of conceptual large-capacity refrigeration systems. A complete systems engineering analysis has been carried out jointly between BNL and tive Long Island Lighting Coupany (LILCO). The resuits of a cost analysi.; of a future requirement of LILCO for a 40-mile 4800 MVA transinission circuit appears encouraging, indicating that superconducting cesign: are significantly less expensive than a conventional HPOF underground system and, in some cases, only a factor of two more expensive than a $345 \mathrm{kV}$ overnead system. Long (50 ft) model cryostats and cables are in preparation with the final goal a $1 / 2$-mile long three-phase cable incorporated in the power feeder systern at the Laboratory.

\section{RF Superconducting Cavities}

This program is directed toward the application of superconducting deflecting cavities to the long-pulse microwave beam separators essential for high energy physics experiments involving countex detectors. Superconducting cavities derive their advantage from the very high quality factors made possible from the reduction of power lasses in the cavity wall surface by several orders of magnitude, compared to those attainable in room temperaturs copper cavities.

The most promising superconductors are lead and nicbirm, because of their comparatively high criticai temperatures and magnetic fields. The Brookhaven program, ${ }^{50-52}$ which is now approximat 21 y teri years old, has concentrated on $\mathrm{Nb}$ which has the greater potentialities of the two materials. A number of test cavities have been assembled and rested althoug: 


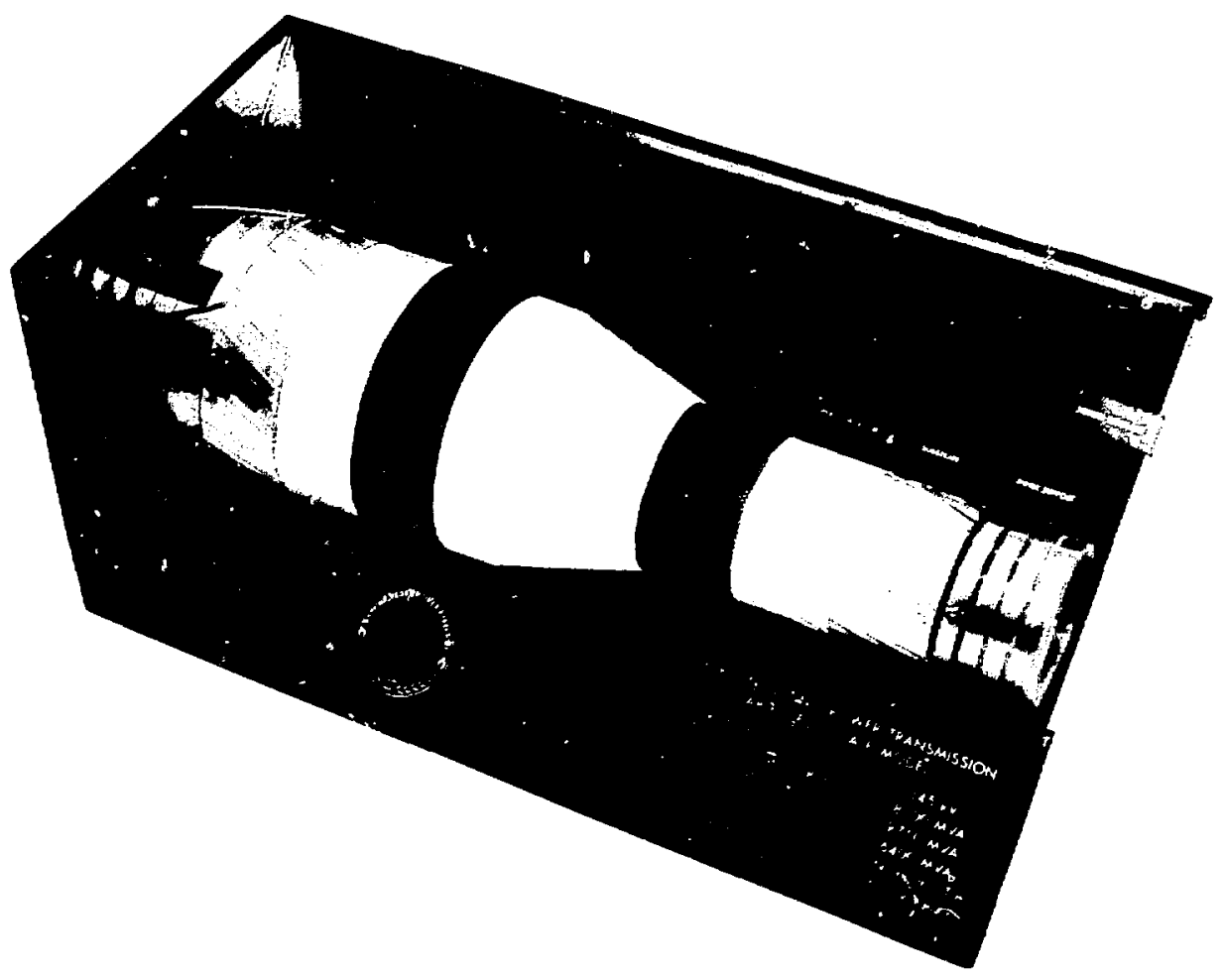

Figure 18. Ful1-scale model of a $345 \mathrm{kV}$ superconducting cable. A circuit using three such cables would be rated at 8100 MVA, or approximately the power consumed by New York City. 
lack of funds have postponed the actual deployment of deflectors in a beam line. One of these test cavities, a 5-cell cevity in a continuing study of $\mathrm{S}$-band $(2.85 \mathrm{GHz})$ deflectors for application to separators in the momentum range of the AGS, nas achieved a quality factor $Q$ of about $4 \times 10^{9}$, and a peak field of 410 gauss corresponding to an equivalent deflecting field of over $2 \mathrm{MV} / \mathrm{m} .53$ A more recent cavity is illustrated by a 7-cel1 $\mathrm{X}$-band (8.66 GHz) structure (shown in Fig. 19) completed to aid the design of a separator suitable for the higher momenta at the National Accelerator Laboratory. $^{54}$ It attained a peak magnetic field of 740 gauss, a record to date corresponding to a peak electric field of $25 \mathrm{MV} / \mathrm{m}$ or a deflecting field of $6.9 \mathrm{MV} / \mathrm{m}$, and a $Q$-value of $4.5 \times 10^{9}$.

While these tests on geometrically simple cavities confirm that quality factors and peak fields well above required performance can in principle be achieved, their realization depends critically on the method of fabrication as well as post-fabrication treatment. The Brookhaven cavities are machined in a series of steps from a solid billet of electron beam melted reactor grade $\mathrm{Nb}$, with all joints electron beam welded. Subsequent surface treatment consists of chemical polishing, anodizing, and heat treatment in a ultra-high vacuum. In spite of these elaborate treatments, initial cavity results are not always reproducible and their extrapolation to different field configurations, frequencies or geometries often unreliable. This has necessitated a more fundamental investigation of metallurgical properties and factors influencing breakdown fields, in which different materials and different treatments are studied in a systematic way. 55 Peak fields of single and polychrystalline specimens are compared, enabling the effects of grain boundaries to be evaluated, and the influence of impurity inclusions, electron beam welding, anodizing, and surface smoothness on the peak rf fields and residual losses are investigated. In addition, the effect of proton irradiation on cavity performance are studied. These efforts are also of continuing importance in the development of cavities for superconducting linear accelerators.

\section{Future Trends}

We conclude this account with some comments on aspects of the BNL superconductivity program in the near future. The dominating factor likely to effect its course at the time of writing is the exciting prospect for the eventual construction of a large accelerator based on 


$$
\not
$$


superconducting magnets. A detailed proposal for the proiected iSA facility has been prepared and construction initiated of a full scale prototype magnet of the type described in Section 5. This dipole will be 4.25 meter long with an inner coil diameter of $12 \mathrm{~cm}$, and weigh approximately $4300 \mathrm{~kg}$. It is designed to produce a 40-kG field of the necessary high homogeniety over an aperture of $8 \mathrm{~cm}$, and should be operational by the middle of 1975 . As we have indicated, however, the strong possibility of successful A-15 multifilamentary materials may have a considerable impact on the ISA design by allowing operation in the $8-9 \mathrm{~K}$ range and at $60 \mathrm{kG}$, and may effect other programs as wel1. The design of a one-meter long dipole using $\mathrm{Nb}_{3} \mathrm{Sn}$ in this form is already in progress, and the conductor is presently being manufactured. In addition, $60 \mathrm{~kg}$ versions of the window frame type are being pursued for several uses.

The continuing experimental physics program of the Laboratory calls for a beam transport system in a new High Energy Unseparated Beam line which must supply particles of momentum up to $30 \mathrm{GeV} / \mathrm{c}$ from the AGS to a large-volume multiparticle spectrometer. This will be the most ambitious superconducting beam transport system undertaken to date, requiring four 2.5-meter long dipoles of peak field $40 \mathrm{kG}$ and possessing a warm aperture of $20 \mathrm{~cm}$ diameter. (Four superconducting quadrupoles, each 1.5 meter long and capable of a gradient of $3 \mathrm{kG} / \mathrm{cm}$ over the same aperture, were also originally intended for this beam line, but limitation on resources has necessitated conventional rom-temperature focusing magnets instead.) These magnets will be essentially shorter (and larger cross-section) versions of the ISA magnets, based on the same mechanical design. Therefore, in addition to the considerable savings in electrical power costs, they should provide both invaluable experience in the operation of a large scale cryogenic system generally and, specifically, further experience directly relevant for the ISA project.

From a broader point of view, the ongoing multidisciplinary research effort in superconductivity at BNL, spanning both applied and very fundamental work, should continue to yield substantial and manifold contributims to the basic physics of superconductors, to superconducting magnet technology, power transmission and electrical machinery, microwave cavities and particle accelerators. It could have profound implications not only for the course of the U.S. high energy physics program over the foreseeable future, but for the eventual success of controlled thermonuclear research programs and ultimately for the electrical industry as a whole. 


\section{References}

1. J. E. Kunzler, E. Bachler, F.S.L. Hsu, and J.E. Wernick, Phys. Rev. Lett. 6, 89 (1961).

2. H. Brechna, "Superconducting Magnet Systems", Springer-Verlag, Heidelberg, New York, 1973.

3. M.N. Wilson, C.R. Walters, J.D. Lewin, and P.F. Smith, J. Phys. D 3, 1518 (1970).

4. P.G. Kruger, Proc. 1963 Summer Study on Storage Rings, Accelerators and Experimentation at Super-High Energies, Brookhaven National Laboratory, 1963, p.417, (BNL 7534).

5. W.B. Sampson, Rev. Sci. Instrum, 36, 565 (1965).

6. W.B. Sampson, BNL Accelerator Dept. Informal Report AADD-111 (1966).

7. W.B. Sampson, M. Strongin, and G.M. Thomson, BNL Accelerator Dept. Informal Report AADD-99 (1966).

W. B. Sampson, M. Strongin, and G.M. Thomson, Appl. Phys. Lett. 8, 191 (1966).

8. R. Cool, et al. Phys. Rev. D 10, 792 (1974).

9. W.B. Sampson, Proc. Int. Symp, on Magnet Technology, SLAC, Stanford, 1965 , p. 530.

10. S.K. Hilal, W.J. Michelsen, J, Driller, and E. Leonard, Medical Res. Eng. 8, 11 (1969).

11. R.B. Britton, Proc. 1968 Sumener Study on Superconducting Devices and Accelerators, Brookhaven National Laboratory, 1969, p. 679 (BNL 50155).

12. R. B. Britton, F.J. Abbatiello, K.E. Robins, Proc. 4th Int. Conf. on Magnet Technology, Brookhavan, 1972, p. 703.

13. D.F. Brown, R.W. Burgess, and G.T. Mulholland, Proc. 1968 Summer Study on Superconducting Devices and Accelerztors, Brookhaven National Laboratory, 1969, p. 794 (BNL 50155).

14. Z.K. Hand and W.K.H. Panofsky, Rev. Sci. Instrum. 30, 927 (1959). 
15. P.G. Kruger, W.B. Sampson, and R.B. Britton, BNL Accelerator Dept. Informa 1 Report AADD-104-R (1966).

P.G. Kruger, W.B. Sampson, and R.B. Britton, IEEE Trans. on Magnetics MAG-2, 338 (1966).

16. R.A. Beth, IEEE Trans. Nucl. Sci. NS-14, 386 (1967).

17. W.B. Sampson, Proc. Int. Conf. on Magnet Technology, Oxford, 1967, p. 574.

18. Ibid., p. 575.

19. R.B. Britton, Proc. 1968 Summer Study on Superconducting Devices and Accelerators, Brookhaven National Laboratory, 1969, p. 893 (BNL 50155).

20. R.A. Beth, BNL Accelerator Dept. Informal Report AADD-220 (1966).

21. J.P. Blewett, Proc. 1968 Summer Study on Superconducting Devices and Accelerators, Brookhaven National Laboratory, 1969, p. 1042 (BNL 50155).

22. J.J. Grisoli and H.C.H. Hsieh, BNL Accelerator Dept. Technical Note No. $75(1970)$.

23. H. Hsieh, R. Britton, R. Gibbs, J. Grisoli, and H. Kapfer, Proc. 4th Int. Conf. on Magnet Technology, Brookhaven, 1972, p. 157.

24. G. Danby, H. Foelsche, S. Hsieh, J. Jackson, A. Prode11, Ibid,, p. 334.

25. J. Allinger, G. Danby, B. DeVito, R. Gibbs, S. Hsieh, J. Jackson, A. Prode11, and A. Raag, Proc. 1972 Applied Superconductivity Conference, Annapolis, 1972, p. 293.

26. J. Allinger, G. Danby, B. DeVito, H. Foelsche, R. Gibbs, S. Hsieh, J. Jackson, A. Prode11, and A. Raag, Proc. 4th Int. Conf. on Magnet Technology, Brookhaven, 1972, p. 758 .

27. J. Allinger, G. Danby, B. DeVito, S. Hsieh, J. Jackson, and A. Prodell, IEEE Trans. Nuc1. Sci. NS-20,678 (1973).

28. J. Allinger, G. Danby, B. DeVito, H. Foelsche, S. Hsieh, J. Jackson, and A. Prode11, Proc. IX Int. Conf. on High Energy Accelerators, SLAC Stanford, 1974 (in press).

29. "Design Study of a Cold Magnet Synchrotron (CMS)", BNL 15430, A. van Steenbergen, Editor, 1970. 
30. "A Proposal for Construction of a Proton-Proton Storage Accelerator Facility ISArELLE", BNL 18891, H.Hahn and M. Plotkin, Editors, 1974.

31. P.F. Dah1, G.H. Morgan, and W.B. Sampson, J. App1. Phys. 40, 2083 (1969).

32. W.B. Sampson, P.F. Dahl, A.D. McInturff, and K.E. Robins, IEEE Trans. Nucl. Sci., NS-18, 660 (1971).

33. Ibid., p. 661 .

34. A.D. McInturff, P.F. Dainl, and W.B. Sampson, J. Appl. Phys. 43, 3546 (1972).

35. W.B. Sampson, R.B. Britton, P.F. Dahl, A.D. McInturff, G.H. Morgan, and K.E. Robins, Particle Accelerators $\underline{1}, 1973$ (1970).

36. J.E. Allinger, G.T. Danby, J.W. Jackson, and S.T. Lin, Proc. 4th Int. Conf. on Magnet Technology, Brookhaven, 1972, P. 637.

37. P.F. Dah1, R. Damm, D.D. Jacobus, C. Lasky, A.D. McInturff, G.H. Morgan, G. Parzen, and W.B. Sampson, IEEE Trans. Nuc1. Sci. NS-20, 688 (1973).

38. G.H. Morgan, BNL Accelerator Dept. Informal Report AADD-145 (1968).

39. G.H. Morgan, Proc. 4th Int. Conf. on Magnet Technology, Brookhaven, 1972, P. 787 .

40. G. Parzen and K. Jellett, BNL Accelerator Dept. Informa 1 Report AADD-165 (1970).

41. W.B. Sampson, P.F. Dahl, A.D. McInturff, and K.E. Robins, Proc. IX Int. Conf. on High Energy Azcelerators, SLAC, Stanford, 1974 (in press).

42. A.R. Kaufman and J.J. Pickett, Bull. Am. Phys. Soc. 15, 838 (1970).

43. M. Suenaga and W.B. Sampson, App 1. Phys. Lett. 18, 584 (1971).

44. M. Fachikawa, Proc. 1972 Applied Superconductivity Conference, Annapolis, 1972, p. 371.

45. M. Suenaga and W.B. Sampson, Appl. Phys, Lett. 20, 443 (1972).

46. J.E. Crow and M. Suenaga, Pruc. 1972 Applied Superconductivity Conference, Annapolis, 1972 , P. 472.

47. "Underground Power Tránsmission by Superconducting Cable", BNL 50325, E.B. Forsyth, Editor, 1972.

48. E.B. Forsyth, M. Garber, J.E. Jensen, G.H. Morgan, R.B. Britton, J.R. Powell, J.P. Blewett, D.H. Gurinsky, and J.M. Hendrie, Proc. 1972 Apolied Superconductivity Conference, Annapolis, 1972, p. 202. 
49. M. Suenaga and M. Garber, Science 183, 952 (1974).

50. H.J. Halama and H. Hahn, IEEE Trans. Nuc 1. Sci. NS-14, 350 (1967).

51. H. Hahn and H.J. Halama, Ibid., P. 356.

52. H.J. Ha lama, Proc. 1968 Summer Study on Superconducting Devices and Accelerators, Brookhaven National Laboratory, 1969, p. 150 (BNL 50155).

53. J.R. Aggus, W. Bauer, S. Giordano, H. Hahn, and H.J. Halama, IEEE Trans. Nucl. Sci. NS-20, 95 (1973).

54. J.R. Aggus, W. Bauer, S. Giordano, H. Hahn, and H.J. Ha lama, App 1. Phys. Lett. 24, 144 (1974).

55. W. Bauer, S. Giordano, and T. Luhman, BNL Accelerator Dept. Informal Report AADD 73-11 (1973).

PFD:as

$8 / 14 / 74$

Distr.: B2, B3, AADD External 